\title{
Failure Analysis of Intersections of Large-Scale Variable Cross-Section Roadways in Deep Soft Rock and Study of Integrated Control Technology of Bolting and Grouting
}

\section{Shengrong Xie}

China University of Mining and Technology - Beijing Campus

\section{Yiyi Wu}

China University of Mining and Technology - Beijing Campus

Dongdong Chen ( $\nabla$ chendongbcg@163.com )

China University of Mining and Technology - Beijing Campus https://orcid.org/0000-0002-4504-8142

Ruipeng Liu

China University of Mining and Technology - Beijing Campus

\section{Xintao Han}

China Coal Technology and Engineering Group Corp China Coal Research Institute

\section{Qiucheng Ye}

China University of Mining and Technology - Beijing Campus

\section{Research}

Keywords: Deep soft rock, variable cross-section, roadway intersection, bolting-grouting integration, new grouting material

Posted Date: July 13th, 2021

DOI: https://doi.org/10.21203/rs.3.rs-701771/v1

License: (c) (i) This work is licensed under a Creative Commons Attribution 4.0 International License. Read Full License 


\title{
Failure analysis of intersections of large-scale variable cross-section roadways in deep soft rock and study of integrated control technology of bolting and grouting
}

\author{
Shengrong Xie ${ }^{1}$, Yiyi Wu ${ }^{1}$, Dongdong Chen ${ }^{1, *}$, Ruipeng Liu ${ }^{1}$, Xintao Han ${ }^{2}$, Qiucheng $\mathrm{Ye}^{1}$ \\ ${ }^{1}$ School of Energy and Mining Engineering, China University of Mining \& Technology, Beijing 100083, China; \\ ${ }^{2}$ Mine safety Technology Branch of China Coal Research Institute, Beijing 100013, China
}

\begin{abstract}
In deep underground mining, achieving stable support for roadways along with long service life is critical and the complex geological environment at such depths frequently presents a major challenge. Owing to the coupling action of multiple factors such as deep high stress, adjacent faults, cross-layer design, weak lithology, broken surrounding rock, variable cross-sections, wide sections up to $9.9 \mathrm{~m}$, and clusters of nearby chambers, there was severe deformation and breakdown in the No. 10 intersection of the roadway of large-scale variable cross-section at the $-760 \mathrm{~m}$ level in the Nanfeng working area of the Wuyang Coal Mine. As there are insufficient examples in engineering methods pertaining to the geological environment described above, the numerical calculation model was oversimplified and support theory underdeveloped; therefore, it is imperative to develop an effective support system for the stability and sustenance of deep roadways. In this study, a quantitative analysis of the geological environment of the roadway through field observations, borehole peeking, and ground stress testing is carried out to establish the FLAC 3D variable cross-section crossing roadway model. This model is combined with the strain softening constitutive (surrounding rock) and Mohr-Coulomb constitutive (other deep rock formations) models to construct a compression arch mechanical model for deep soft rock, based on the quadratic parabolic Mohr criterion. An integrated control technology of bolting and grouting that is mainly composed of a high-strength hollow grouting cable bolt equipped with modified cement grouting materials and a high-elongation cable bolt is developed by analyzing the strengthening properties of the surrounding rock before and after bolting, based on the Heok-Brown criterion. As a result of on-site practice, the following conclusions are drawn: (1) The plastic zone of the roof of the cross roadway is approximately $6 \mathrm{~m}$ deep in this environment, the tectonic stress is nearly 30 $\mathrm{MPa}$, and the surrounding rock is severely fractured. (2) The deformation of the roadway progressively increases from small to large cross-sections, almost doubling at the largest cross-section. The plastic zone is concentrated at the top plate and shoulder and decreases progressively from the two sides to the bottom corner. The range of stress concentration at the sides of the intersection roadway close to the passageway is wider and higher. (3) The $7 \mathrm{~m}$-thick reinforced compression arch constructed under the strengthening support scheme has a bearing capacity enhanced by 1.8 to 2.3 times and increase in thickness of the bearing structure by 1.76 times as compared to the original scheme. (4) The increase in the mechanical parameters $\mathrm{c}$ and $\varphi$ of the surrounding rock after anchoring causes a significant increase in $\sigma_{c}$ and $\sigma_{t}$; the pulling force of the cable bolt beneath the new grouting material is more than twice that of ordinary cement grout, and according to the test, the supporting stress field shows that the $7.24 \mathrm{~m}$ surrounding rock is compacted and strengthened in addition to providing a strong foundation for the bolt (cable). On-site monitoring shows that the 60 -day convergence is less than $30 \mathrm{~mm}$, indicating that the stability control of the roadway is successful.
\end{abstract}

Keywords: Deep soft rock; variable cross-section; roadway intersection; bolting-grouting integration; new grouting material

\section{Introduction}

With the exhaustion of shallow coal resources, coal mining in east-central China has shifted to deeper realms (Cai and Brown 2017 ; Chen, et al. 2019). Deep ground stress is high, mining has a considerable influence, surrounding rock deformation has great mobility, expansion, and impact; hence, adequate support of roadways is becoming increasingly problematic (Liu 2011 ; Fairhurst 2017 ; Xie, et al. 2018). A long service life and high stability are essential requirements

\footnotetext{
* Corresponding author: Dongdong Chen

E-mail address: chendongbcg@163.com
} 
in the development of roadways. The environment at great depths is unique owing to the complicated geological conditions (Wagner 2019 ; Ranjith, et al. 2017). The No. 10 intersection examined in this study includes a portion of the roadway of width $9.89 \mathrm{~m}$ with loose and fractured surrounding rock that was seriously damaged by strong tectonic stress at that depth and traverses uneven strata. Consequently, traditional anchor support is inadequate to withstand the significant deformation damage that occurs in practice (Pan, et al. 2017).

Many academics have carried out thorough studies on the control and design of surrounding rocks to address the challenge of providing an appropriate support system for deep roadways in complicated geological settings. Yang, et al. (2017) suggested a support system for deep soft rock submerged roads based on high-strength anchoring, a high-stiffness spraying layer to prevent water, and deep and shallow hole grouting to rebuild the damaged surrounding rock. Xie, et al. (2019) suggested a complete control approach for deep large-section chambers such as strong bolt (cable) support, thick-walled reinforced concrete pouring, and full-section pressure-regulating grouting behind the walls. Kang, et al. (2014) developed a novel form of an integrated support system and floor monitoring technique to prevent and manage the weak floor of a deep roadway. Huang, $\mathrm{Li}$, and Zhang et al. utilized a novel steel pipe concrete reinforced support that successfully suppressed serious deformation of deep roadways(Huang, et al. 2018 ; Li, et al. 2020 ; Zhang, et al. 2018). Wang, et al. (2017) investigated the damage and control mechanisms of deep soft rock roadways and proposed the idea of "high-strength, integrity, and pressure-relief". Yang, et al. (2017) used a combination technique of "bolt-cable-mesh-shotcrete + shell" to successfully control the deformation of a deep soft rock roadway. Wang, et al. (2015) presented a dynamic damage intrinsic model to evaluate the elastic rebound and shear expansion deformation of the surrounding rock during the unloading process and addressed the pre-peak and post-peak phases in their theory of rock damage in deep roadways. Huang and $\mathrm{Li}$ et al. performed a numerical simulation of deep rock cutting and fracture patterns(Huang, et al. 2016 ; Li, et al. 2016). Peng, et al. (2018) in their study of the structural damage process of deep roadways, reported that horizontal stress had a significant impact on the stability of the surrounding rock and developed a multi-stage support system based on the structural features of the roadway bearing. Shreedharan and Kulatilake (2015) employed the 3DEC discrete element technique to assess the stability of a deep coal mine roadway under various sections and support bodies in their numerical simulation of a deep roadway support. Wang, et al. (2020) utilized ABAQUS to create a finite element model under the original support design, suggested a zoned bolt-grouting reinforcement technology, and numerically tested its support impact. Using self-developed random non-destructive testing methodologies and equipment, Zhang, et al. (2017) suggested an early warning system for the integrity of the roadway envelope based on anchor axial load detection.

The above research provided a sound theoretical and engineering foundation for controlling surrounding rocks in deep roadways; however, a majority of the studies focus on a single geological or roadway attribute, such as soft rock, fractured surrounding rock, flooded roadways, or large section chambers, rather than examining the efficient sustenance of deep roadways under the influence of many varying factors. In addition, numerical simulations using a single intrinsic relationship ignore the difference in mechanics between a tunnel envelope and undisturbed rock formations. Moreover, the existing amount of research on the support of variable-section roadways is relatively small, and the numerical modeling of variable-section roadways under inclined coal rock layers is over-simplified, which affects the accuracy of the results. Deep roadways lack a theoretical model of bolt (cable) support based on soft rock environment resulting in an incorrect choice of support materials. The present cement slurry-based grouting material has a large number of flaws; therefore, it is difficult to ensure grouting action in deep roadways.

The intersection of the $-760 \mathrm{~m}$ level No. 10 roadway in the Nanfeng Industrial Zone of the Wuyang Coal Mine is the subject of research in this study, and the coupling impact of many variables such as deep high stress, adjacent faults and interlayer arrangement, weak lithology, fractured surrounding rocks, varied cross-sections, large cross-sections up to $9.9 \mathrm{~m}$ wide, and clusters of neighboring chambers were examined as the reasons for its deformation and collapse. Field observation, borehole peeking, and in-situ stress testing were used to determine the geomechanical characteristics of the 
roadway. The strain-softening features of the surrounding rock in the post-peak stage were modeled and studied, and the internal friction angle and cohesive force weakening law of the rock were deduced. Curve fitting of the triaxial test was performed using FLAC 3D; the inverted parameters were applied to the FLAC 3D variable cross-section roadway model to achieve the coupling of the surrounding rock strain softening and Mohr-Coulomb constitutive model, to effectively analyze the force and deformation characteristics of the roadway intersection. For support design analysis, a thick reinforced compression arch mechanical model, based on the quadratic parabolic Mohr strength criteria, was developed for the surrounding conditions of deep soft rock, and the strengthening support scheme with the action path of "deep hole grouting and anchoring $\rightarrow$ reinforcement of broken surrounding rock $\rightarrow$ mutual cementation into the arch $\rightarrow$ realization of self-supporting surrounding rock" was proposed, i.e., the anchor injection integrated the support technology based on a hollow grouting anchor cable equipped with a modified grouting material. Simultaneously, the impact of changes in the parameters of the surrounding rock mechanics before and after bolting and grouting on strength was evaluated using the Heok-Brown criteria, and a supporting prestress field was constructed to simulate and validate the plan. The roadway was monitored for displacement and borehole detection following on-site construction, and it was observed that the control effect on the stability of the surrounding rock was good, providing a theoretical direction and engineering reference for roadway support under the arduous circumstances at great depths.

\section{Engineering background}

\subsection{Geological profile}

The Nanfeng working area of the Wuyang Coal Mine is equipped with a fully mechanized top-coal caving face that is mainly used in the No. 3 coal seam of the Shanxi Formation in the Qinshui coalfield, and the designed annual output reaches 3.0 Mt/a. The bottom yard of the air intake shaft is located under the No. 3 coal seam with a buried depth of approximately $760 \mathrm{~m}$. The strike of the coal and rock strata is north high and south low by $12^{\circ}$, and west high and east low by $5^{\circ}$. The rock layers traversed by the roadway at the bottom of the shaft are sandy mudstone, thin mudstone, and sandy mudstone interbeds, where the rock is broken. The overall stability is poor and a bedding of V-level unstable rock mass is developed that leads to frequent roof fall in roadway excavation. A comprehensive histogram of the strata is shown in Figure 1.

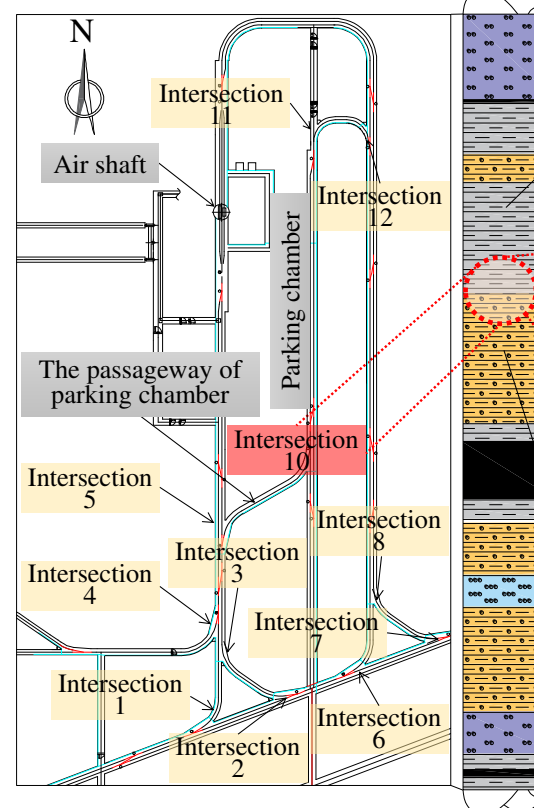

\begin{tabular}{|c|c|c|c|}
\hline \multirow{9}{*}{$\begin{array}{c}\text { Mudstone } \\
11.10 \mathrm{~m}\end{array}$} & Rock stratum & $\begin{array}{c}\text { Thickness } \\
/ \mathbf{m}\end{array}$ & Lithology description \\
\hline & Medium sandstone & 8.70 & $\begin{array}{l}\text { Gray, medium to thick laminated, feldspar, quartz } \\
\text { dominant, uniformly laminated, well sorted, well rounded }\end{array}$ \\
\hline & No.1 coal seam & 0.35 & Black coal line \\
\hline & Mudstone & 5.15 & Gray-black, medium-thick laminated, brittle, flat fracture \\
\hline & Sandy mudstone & 2.75 & Light gray-black, medium-thick laminate, flatter fracture \\
\hline & Mudstone & 11.10 & $\begin{array}{l}\text { Light gray-black, medium-thick laminate, brittle, shell- } \\
\text { like fracture }\end{array}$ \\
\hline & Sandy sudstone & 12.95 & Light gray-black, medium-thick lamellar, jagged fracture \\
\hline & Mudstone & 1.80 & $\begin{array}{l}\text { Gray-black, medium-thick laminated, brittle, shell-like } \\
\text { fracture, containing plant fossils }\end{array}$ \\
\hline & No.3 coal seam & 5.80 & $\begin{array}{l}\text { Black, bright coal mainly, dark coal second, semi-bright } \\
\text { coal }\end{array}$ \\
\hline \multirow{2}{*}{$\begin{array}{l}\text { No. } 10 \text { roadway } \\
\text { intersection }\end{array}$} & Mudstone & 2.35 & Dark gray-black, lumpy, flat fracture \\
\hline & Sandy mudstone & 5.20 & Light gray-black, medium-thick laminated, flat fracture \\
\hline \multirow{6}{*}{$\begin{array}{c}\text { Sandy mudstone } \\
12.95 \mathrm{~m}\end{array}$} & Fine sandstone & 3.20 & $\begin{array}{l}\text { Gray, thickly laminated, quartz dominant, feldspar } \\
\text { secondary, with coal dust, mica, with muddy streaks, } \\
\text { sorted }\end{array}$ \\
\hline & Sandy mudstone & 10.45 & $\begin{array}{l}\text { Dark gray-black, blocky, brittle, flat fracture, containing } \\
\text { plant fossils }\end{array}$ \\
\hline & Medium sandstone & 4.20 & $\begin{array}{l}\text { Gray, medium-thick laminated, feldspar, quartz } \\
\text { dominated, three vertical fissures of } 0.4 \mathrm{~m} \text { in length } \\
\text { developed }\end{array}$ \\
\hline & Mudstone & 1.55 & Dark gray-black, lumpy, brittle, flat fracture \\
\hline & No.3 coal seam & 0.75 & Black coal line \\
\hline & Mudstone & 1.30 & Dark gray-black, lumpy, brittle, flat fracture \\
\hline
\end{tabular}

Fig. 1 Comprehensive histogram of the stratum at the intersection of the roadway

\subsection{Engineering characteristics}

The largest cross-section at the No. 10 intersection is formed by the intersection of people and vehicle parking 
chambers (referred to as parking chambers), and pedestrian and vehicle parking chamber passages (referred to as chamber passages). In view of the geological background of deep high stress, practical conditions of the concentrated chamber group, and large cross-section at the intersection, a comprehensive site observation of the deformation due to the stress environment, characteristics of the surrounding rock, cross-section of the intersection, and construction technology yielded the following characteristics of the project:

(1) Intersections with a concentrated arrangement resulting in stress concentration

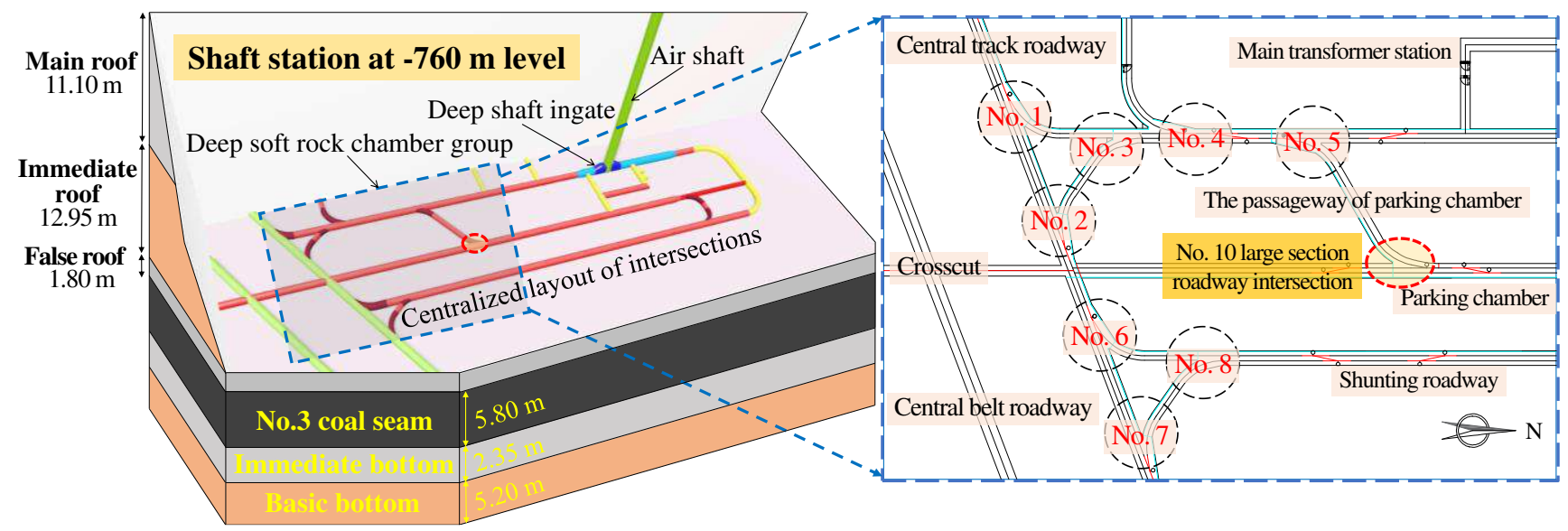

Fig. 2 Location map of all roadway intersections

As shown in Figure 2, 11 roadway intersections connect three transport roadways near the $-760 \mathrm{~m}$ shaft bottom yard in the Nanfeng work area, that form a centralized chamber group along with pipes, pedestrian parking chambers, and horsehead gates. The roof mudstone of the chamber group is not strong and is rich in clay minerals such as a mixed layer of illite/montmorillonite and kaolinite. This makes the surrounding rock soft, strong-swelling, easily attacked by chemicals, and readily weathered(Kang, et al. 2015 ; Yu, et al. 2020). In this environment, densely distributed intersections lead to overlapping stresses. At the largest cross-section at the No. 10 intersection, the range of stress concentration is substantial and the peak stress reaches more than twice the original rock stress. This directly causes severe deformation of the surrounding rock at the intersection giving rise to serious cracking of the shotcrete layer in the roadway.

(2) Poor surrounding rock lithology owing to the proximity of faults and placement through layers

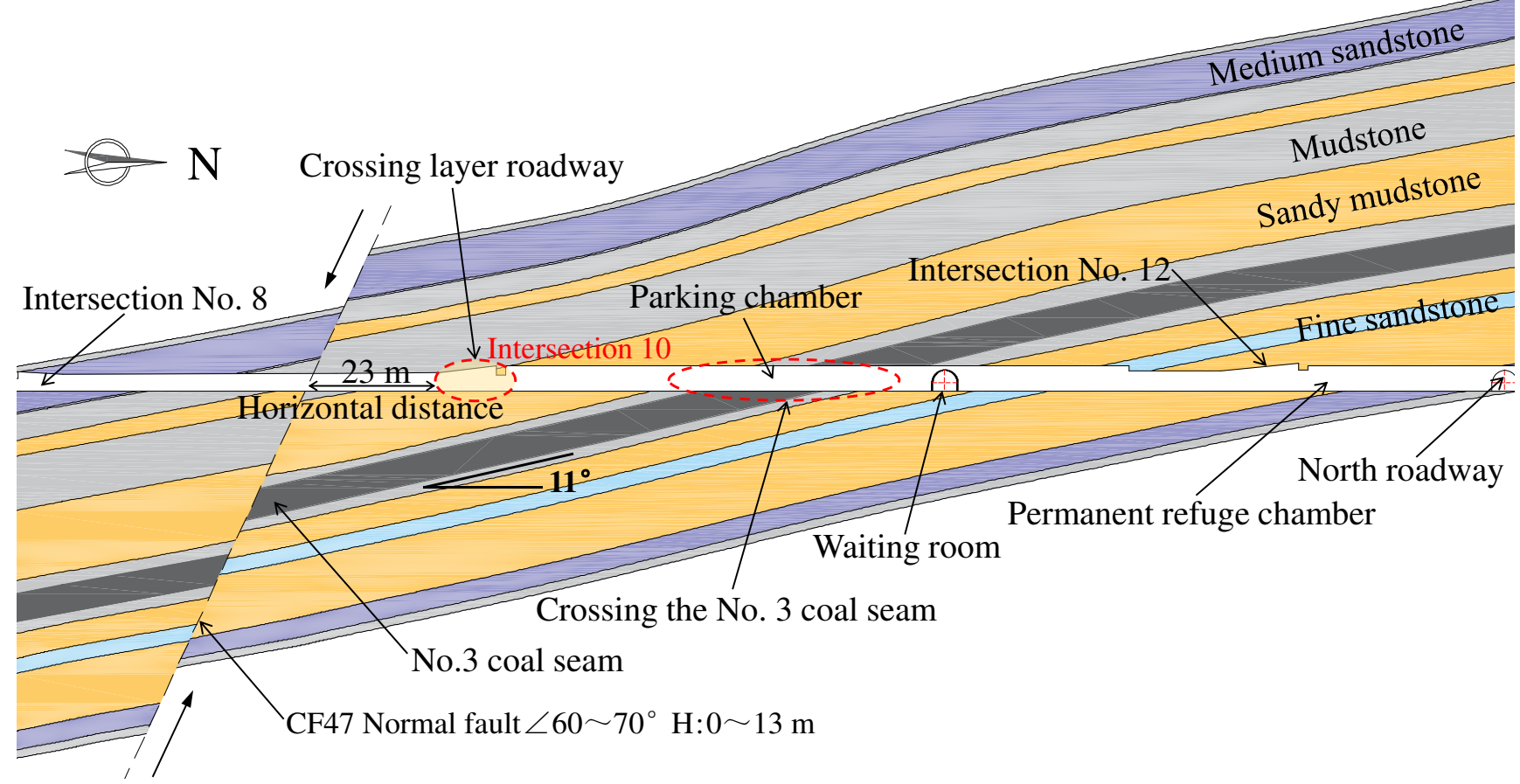


Fig. 3 Stratigraphic profile at the No. 10 intersection

As shown in Figure 3, the south side of the No. 10 intersection is near the positive fault CF47, where the ground stress is dominated by tectonic stress, the surrounding rock strength is low, and integrity is poor. Moreover, the depth of the roadway is large and the surrounding rock of the nearby roadway is broken to some extent, making the support inadequate(Zhang, et al. 2019). The intersection crosses over the junction of the layers of mudstone and sandy mudstone with the bottom of the roadway as the datum, and is almost $0.7-3.0 \mathrm{~m}$ from the datum. Therefore, the No. 10 intersection through the layer triggers the plastic zone in each part to be at a higher level thus increasing the volume of the plastic zone, which directly causes the surrounding rock to be loose and broken.

(3) A large cross-sectional area of the intersection extending the range of disturbance of the surrounding rock

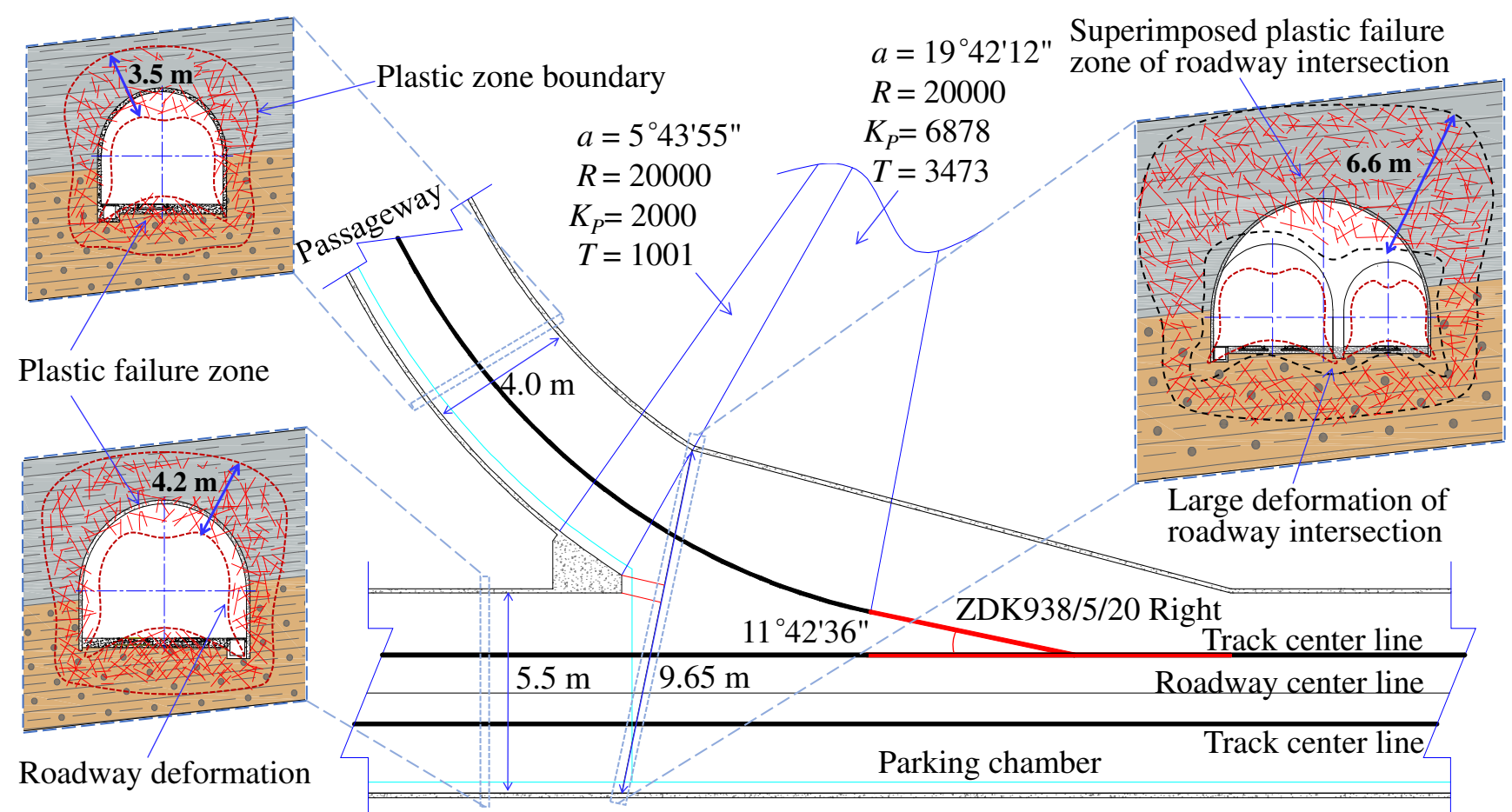

Fig. 4 Schematic of the plastic zone of each section at intersection 10

Figure 4 shows a large cross-section of intersection 10 having an excavation width of $9.89 \mathrm{~m}$. The rock body is in a long-term rheological deformation process; the plastic zone is more developed and creates a wide range of superimposed plastic zones around the junction due to the vast burial depth, enormous section, and fractured surrounding rock(Tan, et al. 2019). Further, the strength and integrity of the surrounding rock at the intersection are poor; hence, the stress causes it to reach the plastic yield condition, leading to plastic flow on both sides of the roadway, as well as shear yield and tensile failure in the region. The actual damage at the comprehensive site intersection, under the effect of strong disturbances, results in overall deformation and instability, and causes chain damage to the cavity group in severe cases.

(4) Difficult construction and maintenance of large cross-sectional intersections.

The occurrence of rib spalling and roof falling is frequent in the process of digging and excavating; the roadway is poorly shaped, especially the No. 10 intersection that is $9.9 \mathrm{~m}$ wide and up to $6.5 \mathrm{~m}$ high. Moreover, the shotcrete layer of the major support section contains cracks and falling blocks; thus, breaking and falling off of the wall takes place to the extent of different degrees during roadway maintenance. Hence, under the conditions of high ground pressure in deep wells, large cross-sections, uneven stratum and superposition of stresses, soft and broken surrounding rock, and complex construction environment, an ordinary bolt (cable) support system cannot effectively maintain the roadway.

\section{Damage deformation analysis}

On account of the field working conditions of the No. 10 intersection, large deformation of the roadway, and broken 
surrounding rock, the methods of drilling peek, in-situ stress measurement, and numerical simulation were used to analyze the surrounding rock plastic zone, roof displacement, and stress conditions.

\subsection{Drilling peek detection}

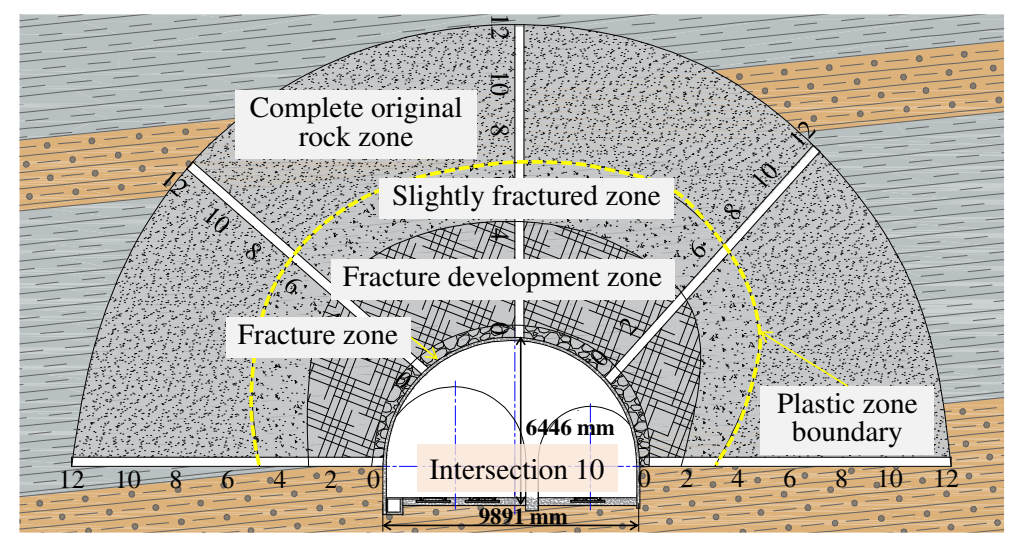

Fig. 5 Schematic of borehole peeking and zoning failure of the surrounding rock

Drilling peeking at intersection 10 is shown in Figure 5: (1) The surrounding rock from $0 \sim 0.4$ m was relatively broken with intense fissures. (2) There was loose destruction of the surrounding rock at a depth of $0.4 \sim 4.2 \mathrm{~m}$, the open fractures were concentrated in the shallow fracture development area, and cracks were developed intensively within a depth of $4 \mathrm{~m}$. (3) There were a large number of fine original fractures in the slight crack area of $4.2 \sim 6.6 \mathrm{~m}$, that reduced from the shallow to deep region. (4) The deep surrounding rock from $6.6 \sim 12 \mathrm{~m}$ was complete with dense rock formations and no obvious cracks. (5) The degree of breakage was greater in the roof and shoulder of the surrounding rock than that at the side; hence, roof control was the focus of our study.

\subsection{In-situ stress measurement}

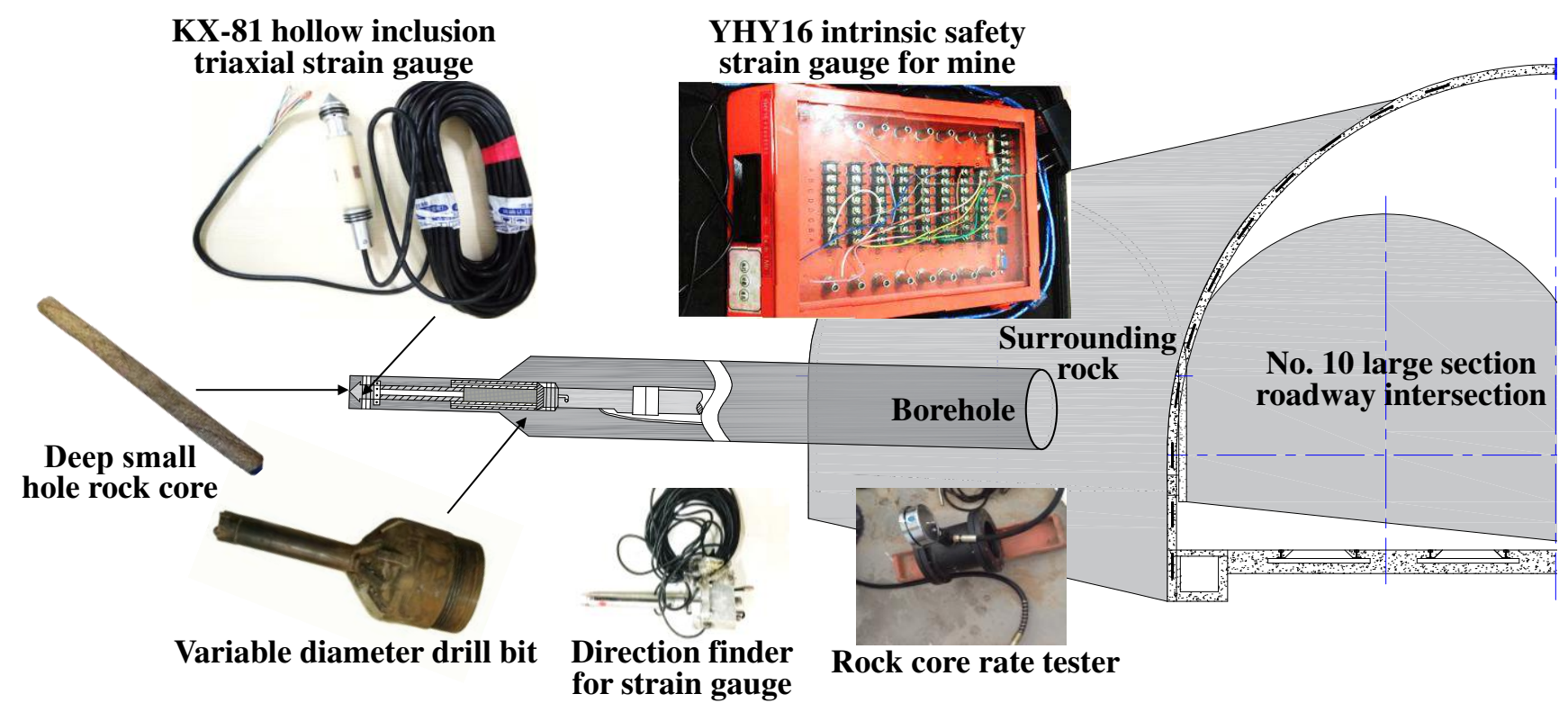

Fig. 6 Schematic of in-situ stress measurement

As shown in Figure 6, an in-situ stress measurement technique based on CSIRO was applied to the field measurements at the No. 10 intersection. The average result of the measured point data showed that the ground stress type was $\sigma_{H}>\sigma_{V}>\sigma_{h}$. The maximum principal stress (near the horizontal direction) of the measuring point was nearly $30 \mathrm{MPa}$ and the average ratio of the maximum principal stress to vertical stress was 1.67 , which is a state of high tectonic stress. The roof and floor control of the roadway support is particularly important in the case of the in-situ stress field dominated by horizontal stress. The roof of the site was soft mudstone with many broken rock blocks, hence, support was difficult. 
Therefore, modification and strengthening of the surrounding rock was the key to forming a support system.

\subsection{Analysis of the failure of the original support scheme}
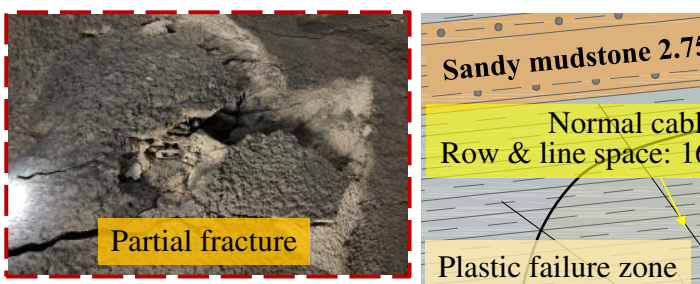

Plastic failure zone

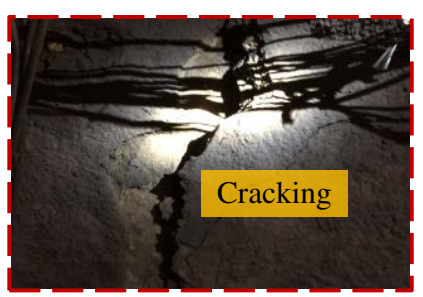

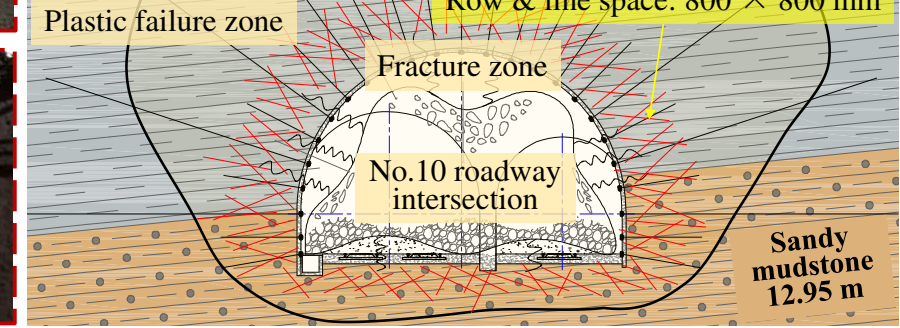

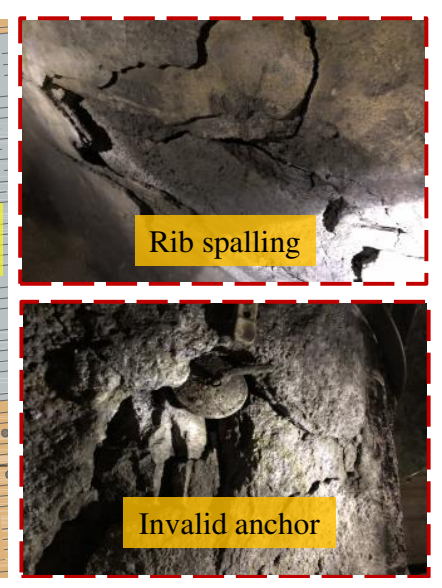

Fig. 7 Schematic of original support scheme and roadway breakdown and deformation

In Figure 7, the original support scheme consisting of an anchor network cable spray + double-steel-bar ladder beam is shown. After the construction, there was large deformation of the roadway section, sinking and cracking of the roof, roof and rib falling, and failure and falling of anchor rods (cables). The original supporting bolts were $2.4 \mathrm{~m}$ long, all of which were in the fracture development concentrated area where they were unable to function; ordinary cable bolts were $7.6 \mathrm{~m}$ long with large spacing and low elongation. The broken surrounding rock did not allow for an effective anchoring foundation, thus the performance of the anchor cable was inadequate and a stable supporting structure was not formed. Hence, the supporting body failed to exert the self-bearing capacity of the surrounding rock.

\subsection{Establishment of FLAC 3D model for No. 10 intersection}

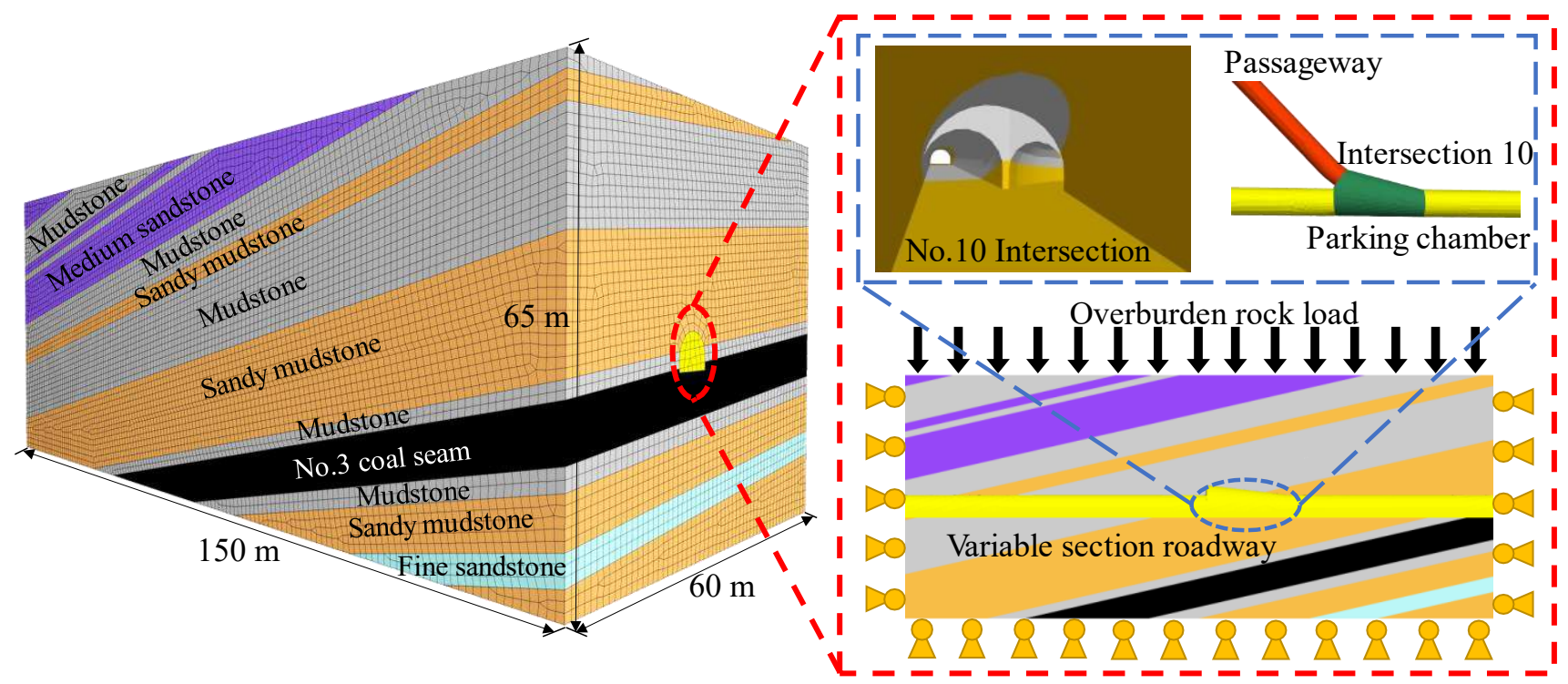

Fig. 8 FLAC 3D numerical model of intersection 10

Based on the engineering geological characteristics of intersection No. 10, a FLAC 3D model that conformed to the actual condition of the site and showed the crossing form of the roadway to the greatest extent was constructed, and is shown in Figure 8. The constitutive relationship of the model adopted the Mohr-Coulomb criterion and the rock formation (mudstone and sandy mudstone) was coupled with the strain-softening constitutive relationship at the intersection point to indicate that the strength of the broken rock was mostly its residual strength. According to the experiment on rock mechanics conducted with the rock core taken from the site, the mechanical parameters of the coal and rock strata given in the following table were adopted for the numerical simulation. 
Table 1 Parameters of coal and rock mechanics used in numerical simulation

\begin{tabular}{ccccccccc}
\hline Rock stratum & $\begin{array}{c}\text { Average } \\
\text { thickness } / \mathrm{m}\end{array}$ & $E / \mathrm{GPa}$ & $K / \mathrm{GPa}$ & $G / \mathrm{GPa}$ & $c / \mathrm{MPa}$ & $\sigma_{t} / \mathrm{MPa}$ & $\varphi /\left(^{\circ}\right)$ & $\gamma / \mathrm{kg} \times \mathrm{m}^{3}$ \\
\hline Medium sandstone & 5.55 & 16.73 & 10.72 & 6.75 & 5.54 & 3.58 & 37.00 & 27.31 \\
Mudstone & 7.65 & 9.66 & 7.00 & 3.80 & 2.83 & 1.19 & 32.00 & 24.63 \\
Medium sandstone & 1.70 & 15.50 & 9.94 & 6.25 & 5.34 & 3.45 & 37.00 & 27.13 \\
Mudstone & 1.30 & 11.34 & 8.22 & 4.46 & 2.62 & 1.12 & 33.00 & 24.66 \\
Medium sandstone & 8.70 & 15.21 & 9.75 & 6.13 & 5.46 & 3.53 & 37.00 & 28.01 \\
Mudstone & 5.50 & 8.69 & 6.30 & 3.42 & 2.34 & 1.05 & 30.00 & 24.14 \\
Sandy mudstone & 2.75 & 12.94 & 8.63 & 5.18 & 4.78 & 2.81 & 35.00 & 25.67 \\
Mudstone & 11.10 & 9.03 & 4.80 & 3.56 & 2.69 & 1.09 & 30.00 & 24.53 \\
Sandy mudstone & 12.95 & 13.65 & 9.10 & 5.46 & 4.92 & 3.12 & 36.00 & 26.46 \\
Mudstone & 1.80 & 10.21 & 7.40 & 4.02 & 2.54 & 1.07 & 32.00 & 24.29 \\
No. 3 coal seam & 5.80 & 5.20 & 4.33 & 2.00 & 1.25 & 0.82 & 25.00 & 14.23 \\
Mudstone & 2.35 & 9.46 & 6.86 & 3.72 & 2.75 & 1.13 & 31.00 & 24.57 \\
Sandy mudstone & 5.20 & 12.30 & 8.20 & 4.92 & 4.62 & 2.80 & 35.00 & 25.49 \\
Fine sandstone & 3.20 & 23.40 & 13.93 & 9.59 & 5.87 & 3.79 & 38.00 & 28.15 \\
Sandy mudstone & 10.45 & 13.50 & 9.00 & 5.40 & 4.75 & 2.76 & 35.00 & 26.06 \\
\hline
\end{tabular}

\subsection{Simulation of strain-softening mechanical characteristics}

(1) Strain softening mechanical model

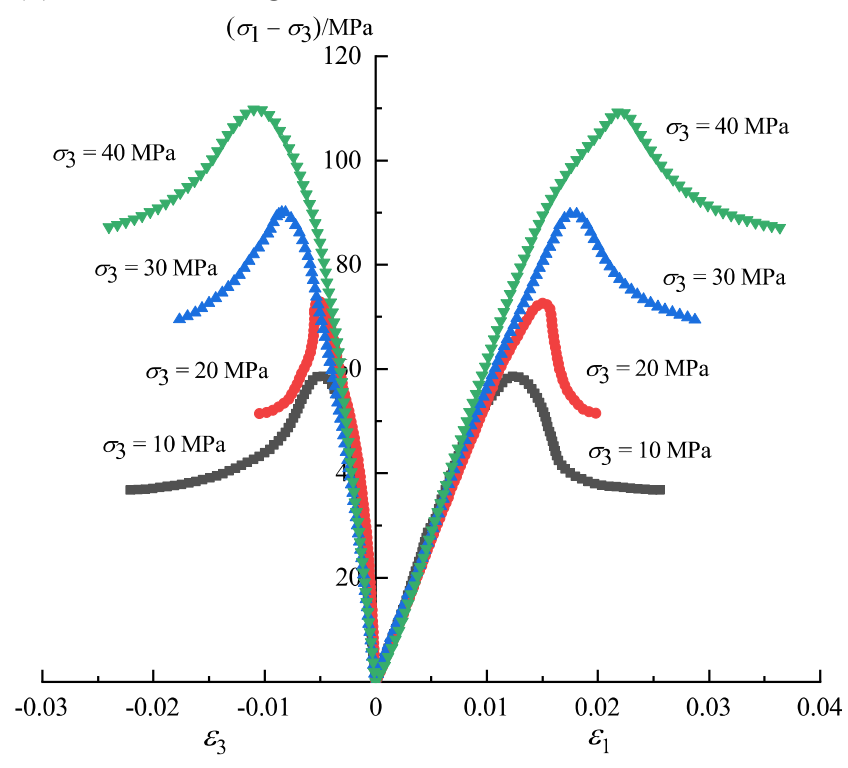

(a) Sandy mudstone

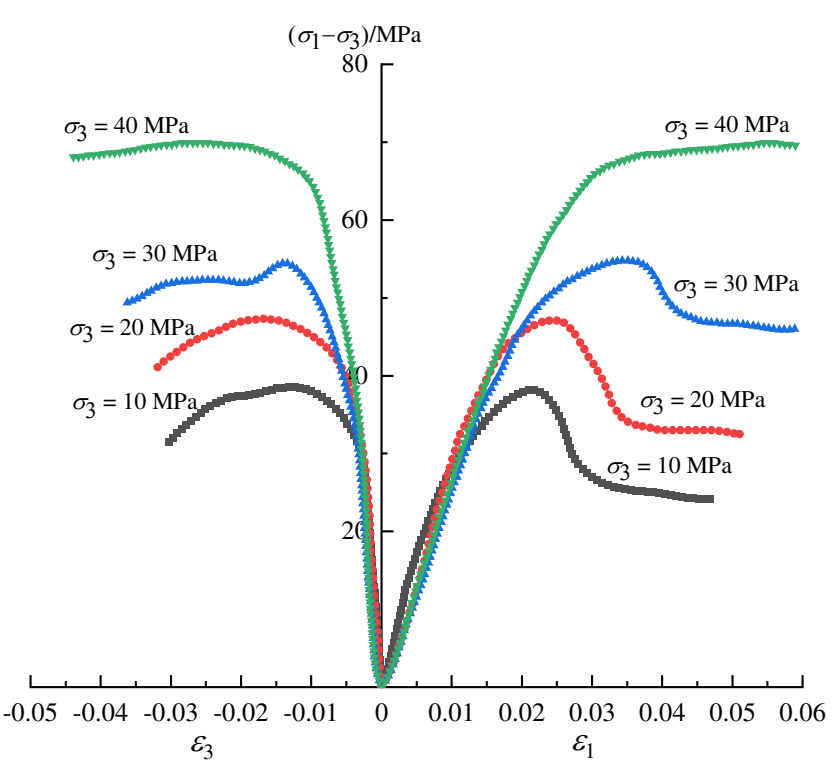

(b) Mudstone

Fig. 9 Full stress-strain curves of two types of rocks under different confining pressures in triaxial compression tests

The No. 10 intersection is at the junction of $12.95 \mathrm{~m}$ sandy mudstone and $11.10 \mathrm{~m}$ mudstone. The surrounding rock is quite broken and the softening characteristics of the post-peak are the main factors affecting the deformation and deterioration of weak rocks. Therefore, based on the results of the triaxial compression test of the two types of rocks shown in Figure 9(Huang, et al. 2014 ; Lu, et al. 2010), an ideal trilinear strain-softening model curve was constructed (Figure 10)(Alonso, et al. 2003 ; Lee and Pietruszczak 2008). As shown in Figure 10 of the simplified model, $O A$ and $O B$ are the pre-peak elastic deformation stages of the rock and the secant of the peak point was used as an approximate replacement. After the peak point, the rock enters the strain-softening stage, where $l$ is the unloading path. Assuming that the unloading process is linearly elastic, there is $l / / O A$, and the same plastic deformation is produced along the unloading 
path $l$ under different confining pressures.

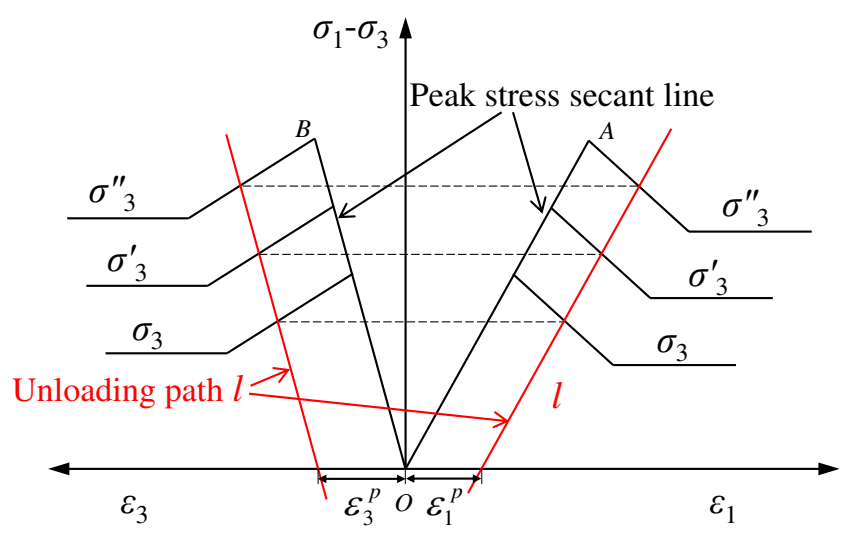

Fig. 10 Post-peak rock strain-softening plastic strain-stress relationship

(2) Yield surface of the strain-softening stage of the rock

Owing to the accumulation of the history of plastic deformation of the rock and randomness of the instantaneous stress state, the subsequent yield surface is different from the elastic stage. To record the history of plastic loading of the rock material, the rock was considered to be anisotropic. The strain-softening parameter $\varepsilon^{p s}$ was used as the plastic state variable (Lu, Wang, Yang, Li and Chen 2010 ; Zhang, et al. 2008) given by the following formula:

$$
\varepsilon^{p s}=\frac{\sqrt{2}}{6} \sqrt{\left(2 \varepsilon_{1}^{p}-\varepsilon_{3}^{p}\right)^{2}+\left(\varepsilon_{1}^{p}+\varepsilon_{3}^{p}\right)^{2}+\left(2 \varepsilon_{3}^{p}-\varepsilon_{1}^{p}\right)^{2}}
$$

where, $\varepsilon_{1}^{p}$ and $\varepsilon_{3}^{p}$ are the principal plastic strain components. Therefore, the subsequent yield surface of the rock after the peak is expressed as

$$
f\left(\sigma_{1}, \sigma_{2}, \sigma_{3}, \varepsilon^{p s}\right)=0
$$

where, $\sigma_{1}$ is the first principal stress, $\sigma_{2}$ and $\sigma_{3}$ are the second and third principal stresses, respectively, and $\sigma_{2}=\sigma_{3}$. It was assumed that the stress state at a point in the post-peak strain-softening stage at different $\varepsilon^{p s}$ is in the critical state of strength failure, i.e., the Mohr-Coulomb criterion is satisfied.

$$
f=\sigma_{1}-\sigma_{3} \frac{1+\sin \varphi^{\prime}}{1-\sin \varphi^{\prime}}+2 c^{\prime} \sqrt{\frac{1+\sin \varphi^{\prime}}{1-\sin \varphi^{\prime}}}
$$

where, the internal friction angle $\varphi$ at the critical state and the cohesive force $c$ under different $\varepsilon^{p s}$ are calculated inversely, and the law of $\varphi$ and $c$ changing with $\varepsilon^{p s}$ of the two types of rocks under study can be obtained simultaneously.

(3) Internal friction angle and weakening law of cohesion 


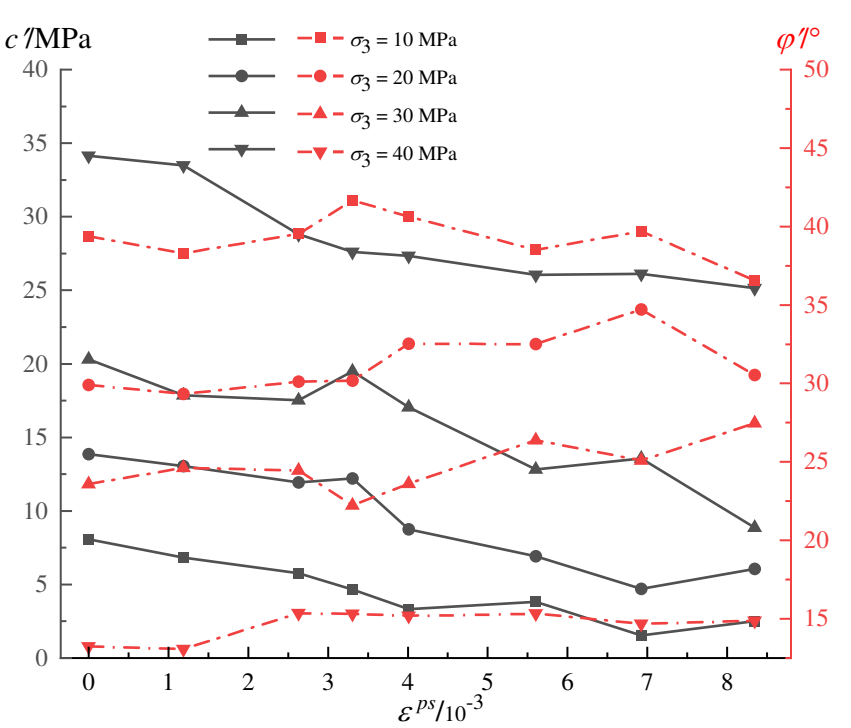

(a) Sandy mudstone

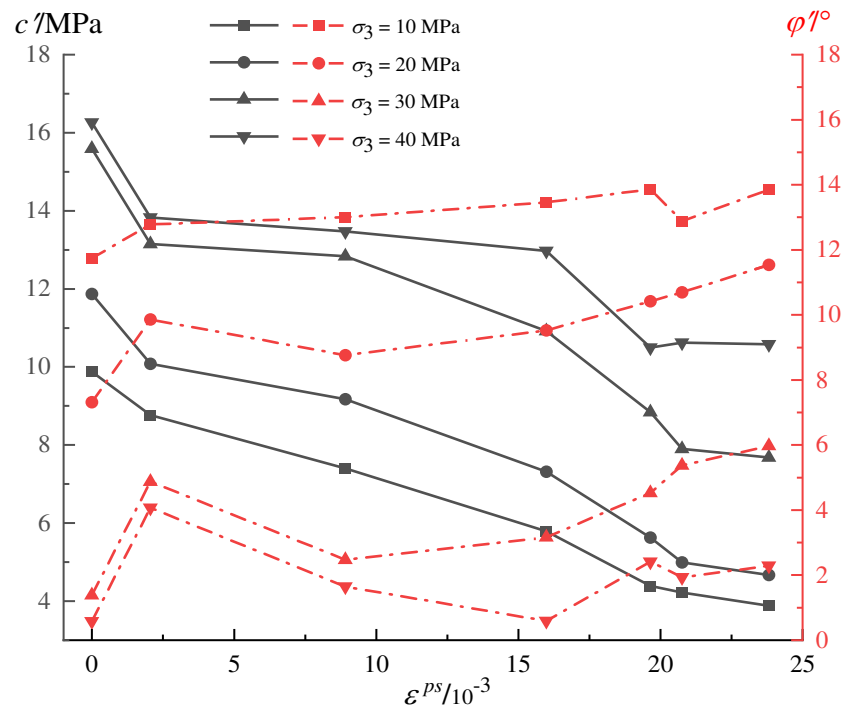

(b) Mudstone

Fig. 11 Curves of the relationship between $c^{\prime}, \varphi^{\prime}$, and $\varepsilon^{p s}$ under different confining pressures

By calculating the values of $c$ and $\varphi$ of the sandy mudstone and the mudstone for 8 groups of different $\varepsilon^{p s}$, the relationship curve was obtained, shown in Figure 11. Under different confining pressures, the values of the cohesive force $c$ of the two types of rocks gradually decreased with an increase in the strain-softening parameter $\varepsilon^{p s}$, whereas the value of $\varphi$ remained unchanged during the strain-softening process. The linear equation was fitted by the downward trend of the two types of rocks $\mathrm{c}$ and the average gradient of the decrease was obtained (Table 2).

Table 2 Parameters of cohesion reduction trend fitting curve

\begin{tabular}{|c|c|c|c|c|c|}
\hline Lithology & $\begin{array}{c}\text { Confining pressure } \\
/ \mathrm{MPa}\end{array}$ & Straight line equation & $\begin{array}{c}\text { Correlation coefficient } \\
\mathrm{R}^{2} \\
\end{array}$ & Average gradient & $\begin{array}{c}\text { Average correlation coefficient } \\
\mathrm{R}^{2}\end{array}$ \\
\hline \multirow{4}{*}{$\begin{array}{l}\text { Sandy } \\
\text { mudstone }\end{array}$} & 10 & $y=-0.7304 x+7.4885$ & 0.8731 & \multirow{4}{*}{-1.0615} & \multirow{4}{*}{0.8569} \\
\hline & 20 & $y=-1.1686 x+14.358$ & 0.8871 & & \\
\hline & 30 & $y=-1.2472 x+20.927$ & 0.8368 & & \\
\hline & 40 & $y=-1.0996 x+32.983$ & 0.8307 & & \\
\hline \multirow{4}{*}{ Mudstone } & 10 & $y=-0.2513 x+9.606$ & 0.9886 & \multirow{4}{*}{-0.2658} & \multirow{4}{*}{0.9418} \\
\hline & 20 & $y=-0.2892 x+11.444$ & 0.9709 & & \\
\hline & 30 & $y=-0.3085 x+15.008$ & 0.9377 & & \\
\hline & 40 & $y=-0.214 x+15.393$ & 0.87 & & \\
\hline
\end{tabular}

(4) FLAC 3D triaxial test simulation
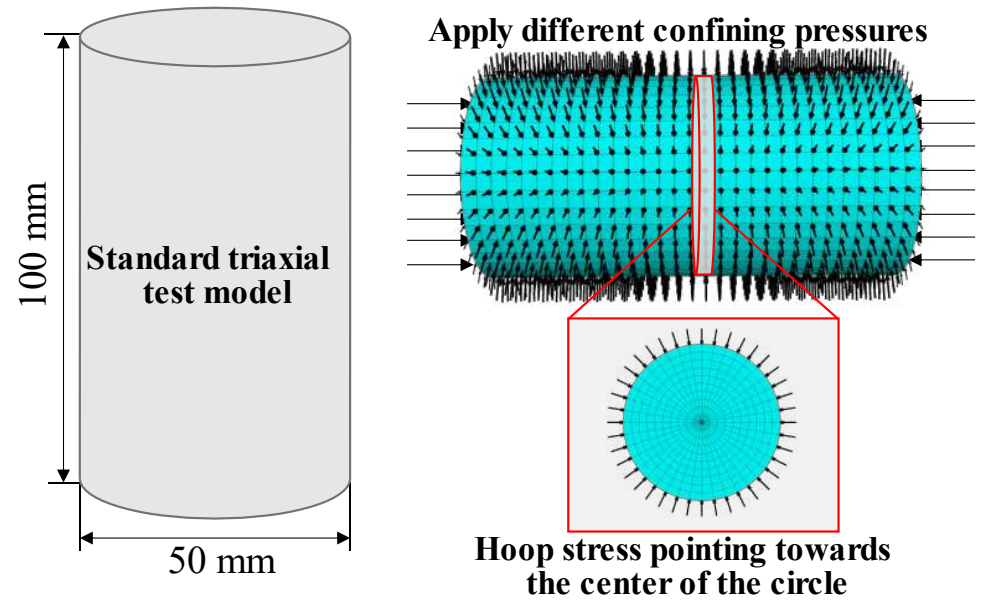

Fig. 12 Model of FLAC 3D triaxial test 
The modified strain-softening model was embedded into the FLAC program to verify the accuracy of the softening model described above. The standard triaxial test model shown was established in FLAC 3D (Figure 12). By applying different confining pressures, the stress-strain curves of sandy mudstone and mudstone based on the above softening model were obtained, and the simulation and experimental curves were compared (Figure 13). The two types of curves were quite consistent proving that the softening model can describe the post-peak mechanical properties of the two types of rocks.

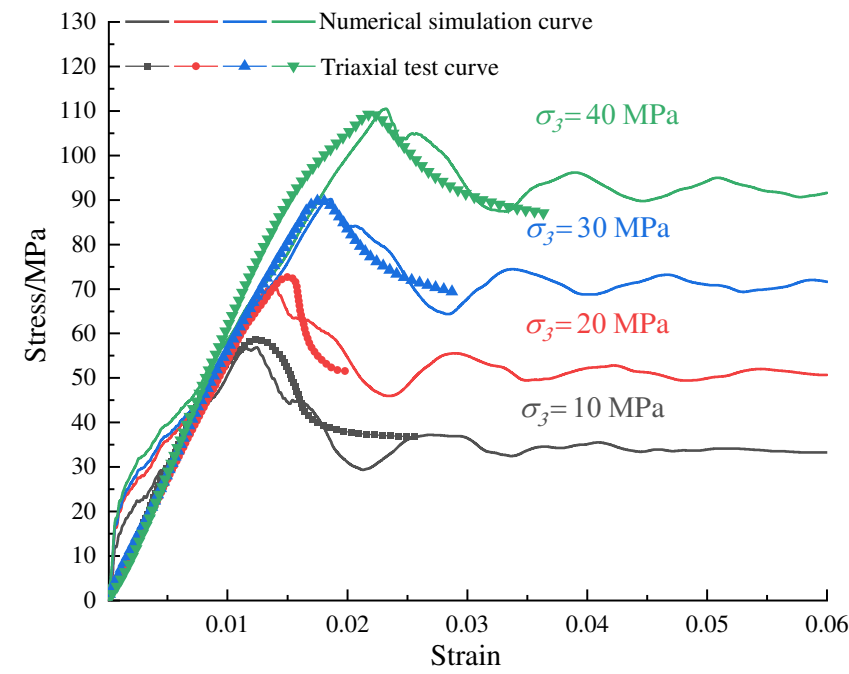

(a) Sandy mudstone

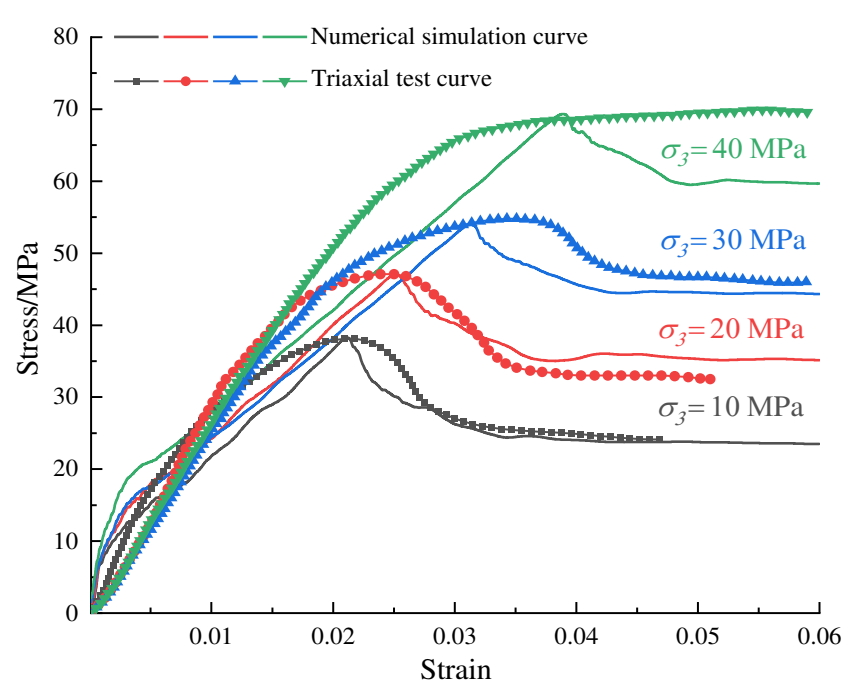

(b) Mudstone

Fig. 13 Fitting graph of numerical simulation and experimental data

\subsection{Analysis of the deformation and force}

(1) Analysis of the displacement

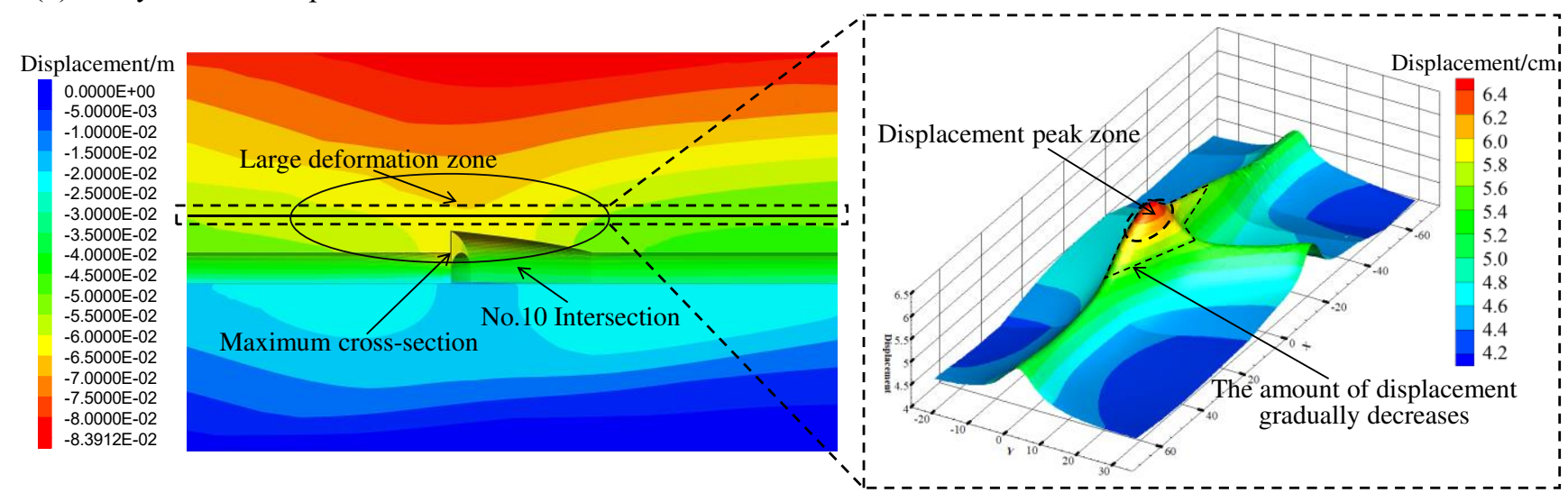

Fig. 14 Vertical displacement cloud of roadway intersection

The displacement of the roof at the intersection was large as compared to that at both the sides of the roadway, especially at the maximum cross-section where it was nearly double; this indicates that the surrounding rock deformation was acute (Figure 14). The range of displacement is clear from the three-dimensional cloud map where the maximum displacement at the roof gradually attenuates from the maximum cross-section of the intersection to the front, rear, and right sides of the roadway. The front and rear attenuation range was approximately $40 \mathrm{~m}$, and that at the right side was approximately $10 \mathrm{~m}$. In engineering practice, roof falling disasters occur frequently at the intersection of roadways during tunneling, therefore, it is difficult to control large cross-sections of roadways.

(2) Analysis of plastic zone 


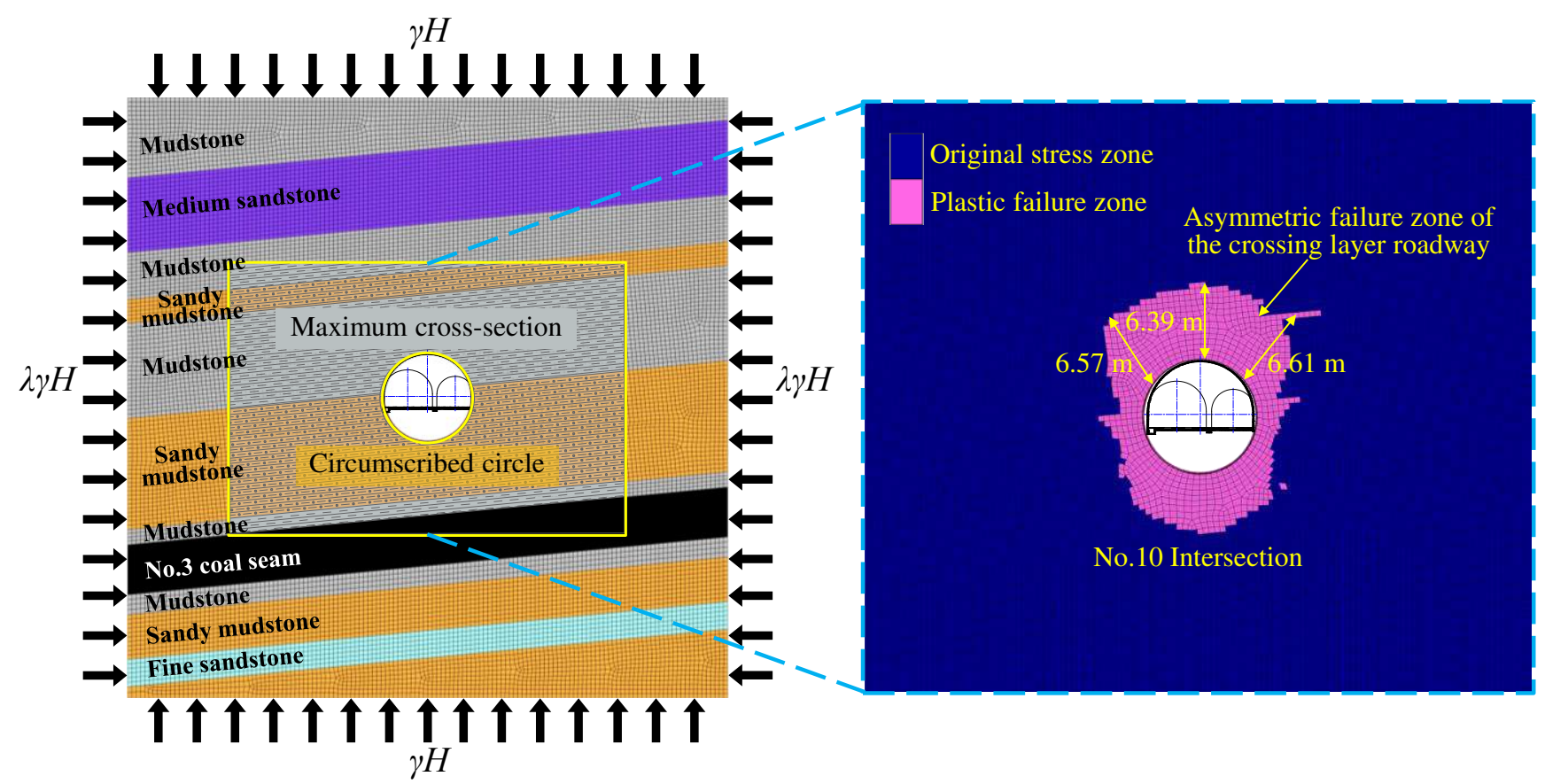

Fig. 15 Cloud map of the plastic zone at intersection 10

The FLAC 3D model of the circumscribed circle of a cross-section of the semi-circular arched roadway at intersection No. 10 was established. According to the results of the in-situ stress test, a vertical stress of $18 \mathrm{MPa}$ and horizontal stress with the lateral pressure coefficient of 1.67 were applied to it. As shown in Figure 15, the plastic zone of the No. 10 cross roadway was $4.2 \sim 6.61 \mathrm{~m}$ deep into the surrounding rock. The range of the plastic zone between the roof and shoulder was wide and reduced gradually from the two sides to the bottom corner. The overall shape of the plastic zone was asymmetric because the roadway passed through the interbedded mudstone and sandy mudstone. The average depth of the plastic zone at the right roof was greater than that at the left roof. The worst case must be considered in devising a support system; therefore, the effective anchorage length of the strengthening support must be greater than the maximum depth of the plastic zone $(6.61 \mathrm{~m})$ and mainly, the roof and shoulders must be controlled.

(3) Analysis of the stress

It is evident from the three-dimensional stress equipotential surface shown in Figure 16 that the value of the stress, concentration coefficient, and range of the roadway intersection are considerably increased. Here, the maximum stress was $42 \mathrm{MPa}$, which was 2.3 times the original rock stress of $18 \mathrm{MPa}$. The stress concentration coefficient at the largest section was greater than 2 , indicating a strong degree of stress concentration. The stress slice of the entire section of the crossing roadway shows that the stress concentration area ranges from $5.65 \sim 6.85 \mathrm{~m}$; the range and degree of stress concentration are higher on the side of the passageway near the roadway intersection.

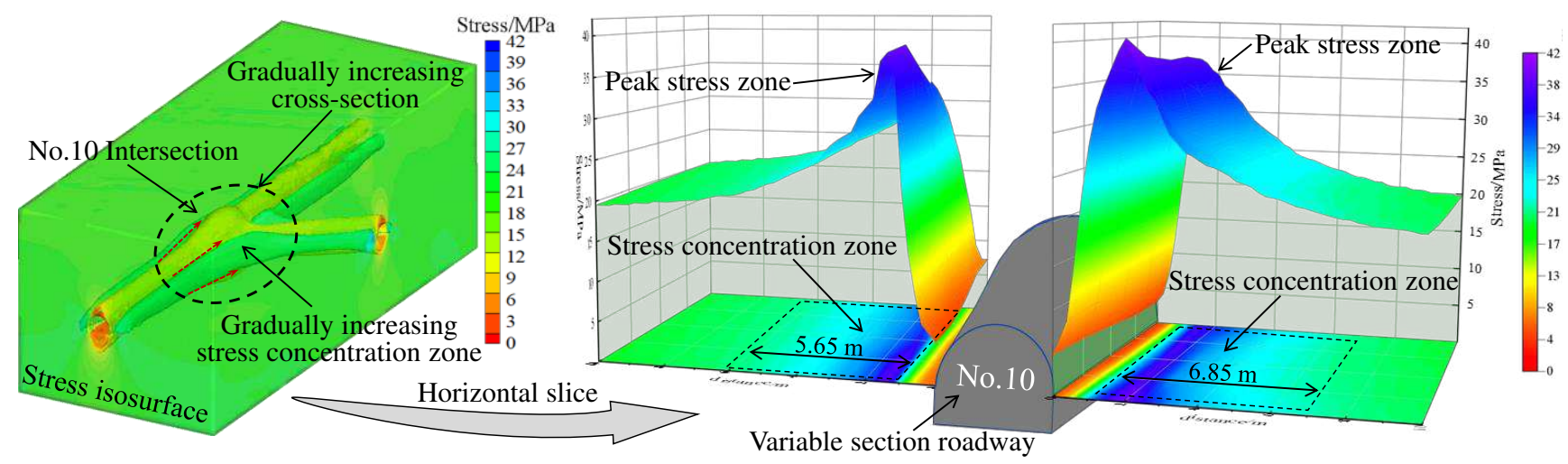

Fig. 16 Cloud map of the stress at intersection 10 


\section{Research on the integration of bolting and grouting support}

\subsection{Construction and analysis of thick reinforced compression arch structure}

In view of the characteristics of the large deformation of the surrounding rock and sizeable range of plastic zones at the No. 10 intersection, and the rapid failure of ordinary support schemes, the design of the strengthening support plan must meet the mechanical properties that can effectively deep anchor and reinforce the plastic zone. A strengthening support scheme with hollow grouting anchor cables combined with high-elongation anchor cables was designed, after an analysis of existing support methods, and is shown in Figure 17 (a). Deep-hole grouting with grouting anchor cables was used to fill the cracks and consolidate the broken rock mass, thus changing its mechanical properties and improving its integrity(Kang, Liu, Gong and Wang 2014); the closed cracks and pores that could not be filled were compressed under the action of pressure. This increased the elastic modulus of the rock mass and its strength correspondingly. The rock mass played a significant role in compaction as it provided a reliable foundation for the anchor cables and built a thick-layered reinforced compression arch with a high bearing capacity. The stability strength of the "surrounding rock-supporting body" thick-layered reinforced compression arch bearing structure was analyzed as follows:

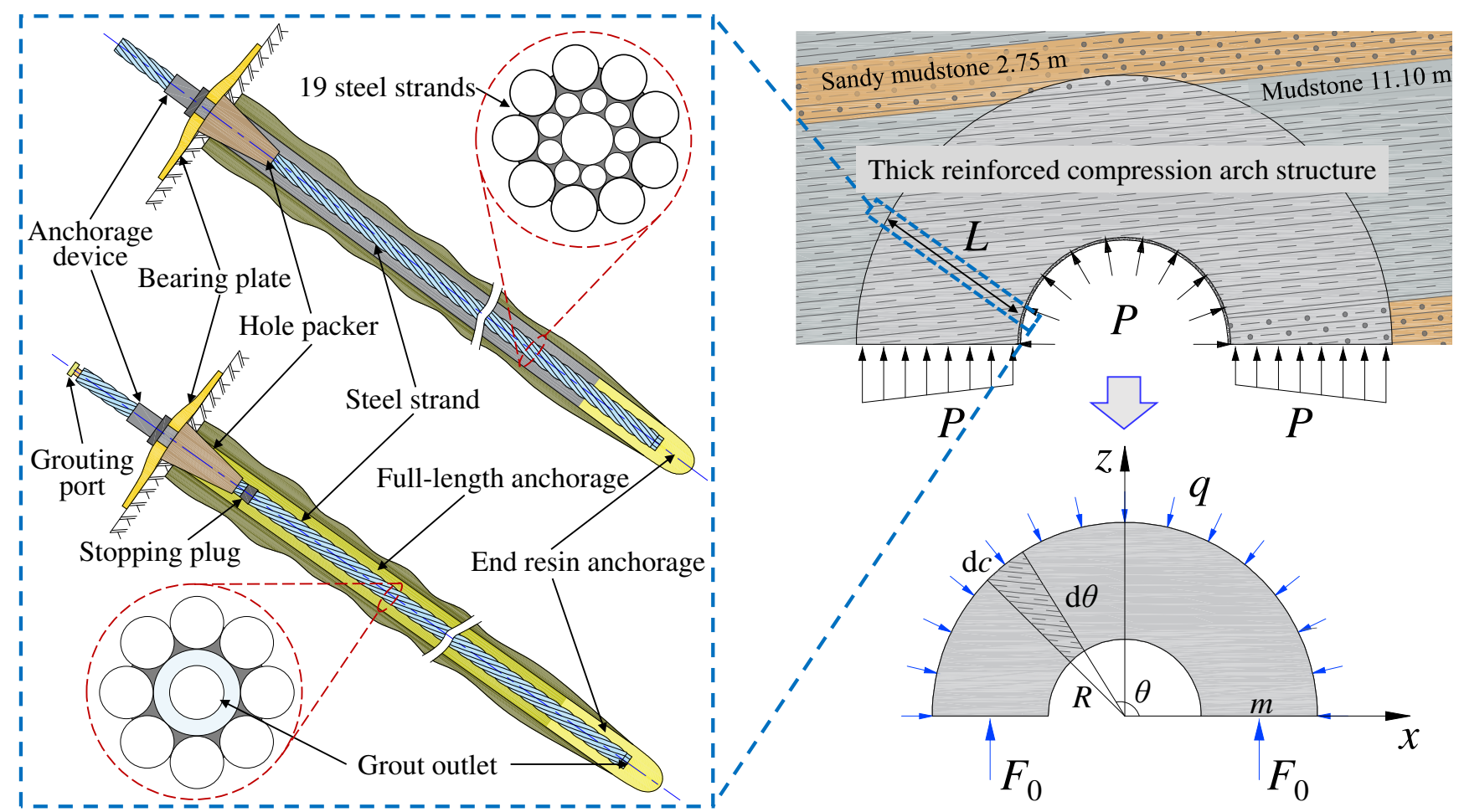

(a) Schematic of hollow grouting cable bolt and high-elongation cable bolt

(b) Mechanical model

Fig. 17 Construction of thick reinforced compression arch structure

The structural mechanics model of the thick-layered reinforced compression arch is shown in Figure 17 (b). $P_{\mathrm{c}}$ and $P_{h}$ are the restraining resistances of the high elongation cable bolt and hollow grouting cable bolt, respectively, and $P$ is the resultant force. The relationship between them is given by

$$
\left\{\begin{array}{l}
P_{c}=\frac{Q_{c}}{L_{c} \cdot W_{c}} \\
P_{h}=\frac{Q_{h}}{L_{h} \cdot W_{h}}
\end{array}\right.
$$

where, $Q_{c}$ and $Q_{h}$ are the drawing forces of the high elongation cable bolt and hollow grouting cable bolt, respectively, and $L_{c}, W_{c}$, and $L_{h}, W_{h}$ are the row and line spaces, respectively.

According to the mechanical properties of the weaker surrounding rock, the supporting rock mass follows the 
quadratic parabolic Mohr criterion( $\mathrm{Li}$, et al. 2006):

$$
\tau^{2}=n\left(\sigma+\sigma_{t}\right)
$$

where, $\tau$ is the shear strength of the supporting rock mass, $\sigma_{t}$ is the tensile strength, and $n$ is an undetermined coefficient.

Under the uniaxial compression test, $n$ can be obtained by using the following formula:

$$
n=\sigma_{c}+2 \sigma_{t} \pm 2 \sqrt{\sigma_{t}\left(\sigma_{c}+\sigma_{t}\right)}
$$

where, $\sigma_{c}$ is the compressive strength of the supporting rock mass.

The principal stress of the quadratic parabolic envelope is expressed as:

$$
\left(\sigma_{1}-\sigma_{3}\right)^{2}=2 n\left(\sigma_{1}+\sigma_{3}\right)+4 n \sigma_{t}-n^{2}
$$

The stress on the inner wall of the arch structure is generally equal to the restraining force of the anchor, i.e.,

$$
\sigma_{3}=P
$$

From equations (4.4) and (4.5), the relation between the principal stress in the limit state and support resistance is obtained as

$$
\sigma_{1}=P+n+2 \sqrt{\left(P+\sigma_{t}\right) n}
$$

To calculate the resultant compressive arch bearing force $\mathrm{F}$ per unit length along the axial direction of the roadway, the calculation principle diagram shown in the figure above was established, and the following differential equation was obtained as

$$
d c=\left(R+\frac{m}{2}\right) d \theta
$$

where, $d c$ is the differential length unit of the outer arc of the compression arch, $R$ is the radius of the crossing roadway, $m$ is the thickness of the backside compression arch, and $d \theta$ is the angle differential unit of the compression arch along the center of the roadway.

From equations (4.6) and (4.7), the resultant compression arch bearing force $F$ is obtained as follows:

$$
F=\left(P+n+2 \sqrt{\left(P+\sigma_{t}\right) n}\right) b+\frac{1}{2} k^{2} m^{2}
$$

where, $k$ is the increasing slope of radial stress.

As anchoring is performed in fractured rock, the following relationship exists:

$$
\left\{\begin{array}{l}
k=0 \\
m=\frac{L \tan \theta-l}{\tan \theta}
\end{array}\right.
$$

where, $L$ is the average length of the bolt(cable), $\theta$ is the control angle of the cable bolt in the supporting rock mass, and $l$ is the row and line space between the supporting bodies. Thus, the expression for $F$ is as follows:

$$
F=\frac{L \tan \theta-l}{\tan \theta}\left(P+n+2 \sqrt{\left(P+\sigma_{t}\right) n}\right)
$$

The circular thick-layered compression arch built on the roadway is affected by the uniformly distributed load $q$ of the deep surrounding rock. Under the action of the total support resistance $P$, the hoop axial force $F_{0}$ produced by the compression arch is expressed as follows: 


$$
2 F_{0}-\int_{0}^{\pi} q \sin \theta \cdot d c=0
$$

Solving the equation, we get

$$
F_{0}=\left(R+\frac{m}{2}\right) q
$$

For the compression arch strength, the total bearing force $F$ must be greater than the hoop axial force $F_{0}$ (i.e., $F \geq F_{0}$ ) to ensure stability of the structural load. When $F=F_{0}$, the compression arch is in the limit of the equilibrium state and the solution is given by

$$
q=\frac{2(L \tan \theta-l)\left(P+n+2 \sqrt{\left(P+\sigma_{t}\right) n}\right)}{\tan \theta(2 R+m)}
$$

Without considering the change in the mechanical parameters of the grouting reinforcement surrounding rock, the measured surrounding rock parameters were substituted in equation (4.13) to obtain a comparison of the bearing capacity of the compression arch formed by the original and strengthened support schemes shown in Figure 18. It can be seen that the thick-layered reinforced compression arch formed by the reinforced support increased the support strength by 1.4 times, making the load-bearing capacity $1.8 \sim 2.3$ times that of the original support, and the thickness of the load-bearing structure formed was increased by 1.76 times. Therefore, the construction of a thick-layered reinforced compression arch was achieved theoretically.

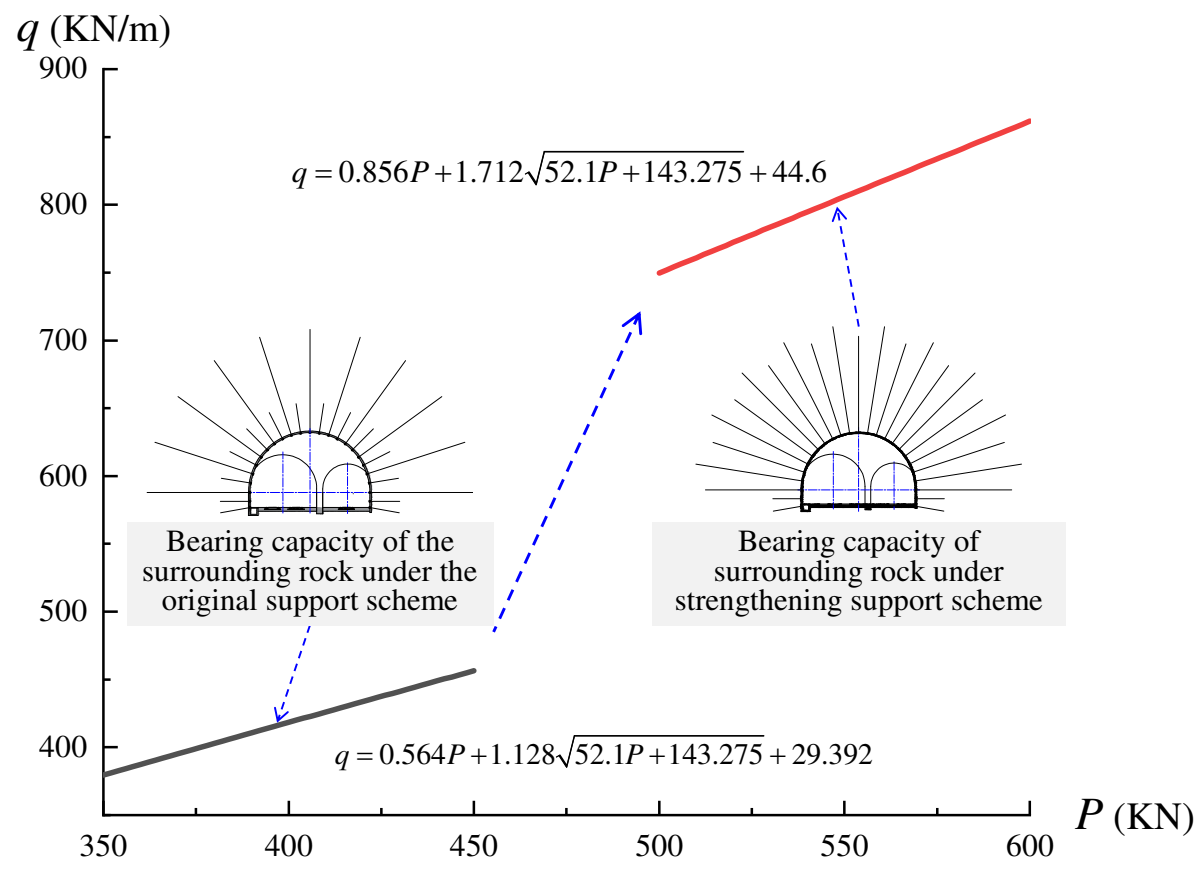

Fig. 18 Comparison of bearing capacity of compression arch under original and reinforced support schemes

\subsection{Mechanism of bolting-grouting integrated stability control}

Anchor-grouting integrated stability control support technology refers to the collaborative implementation of the (i) bolt with the function of "supporting" and "pressure relief," (ii) cable bolt with the function of "control" and "restriction," and (iii) hollow grouting cable bolt with the function of "strengthening" and "compacting," in addition to the "filling" and "consolidation" role of the shotcrete support to achieve stability control over the large cross-section roadway at the intersection. The principle of its action is shown in Figure 19 (a). 


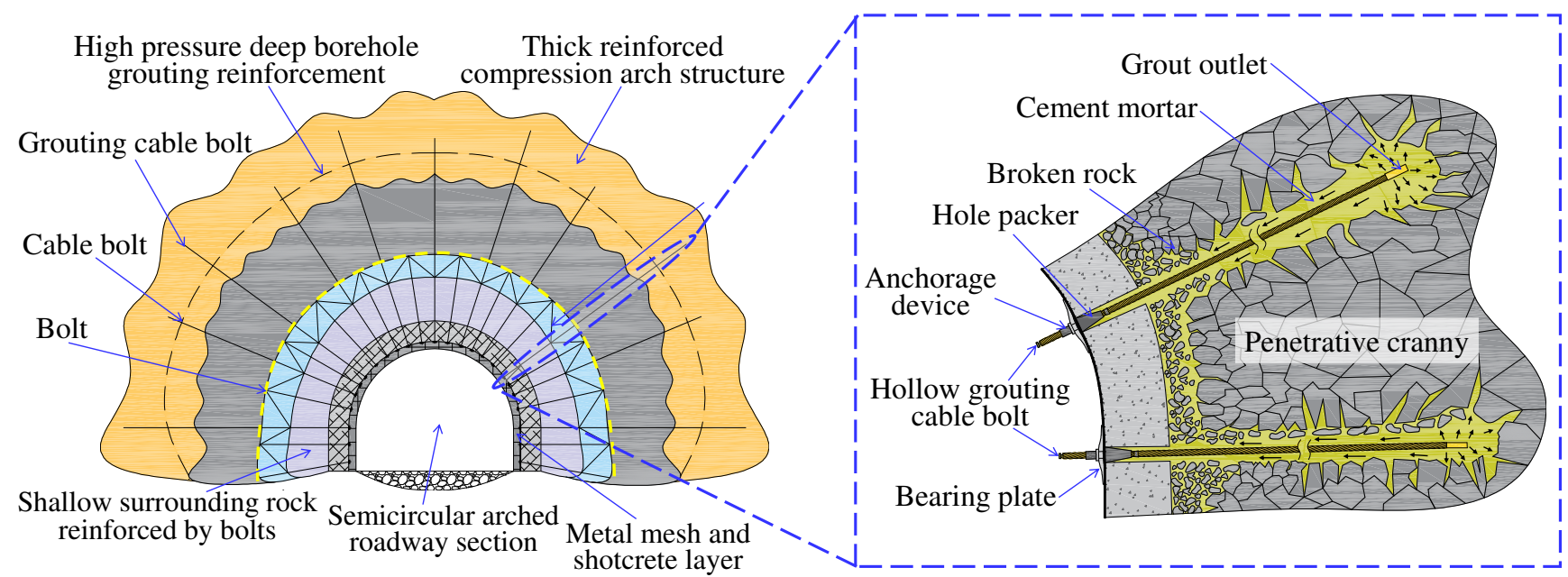

(a) Schematic of anchor-grouting integrated stability control

(b) Schematic of deep hole grouting.

Fig. 19 Principle of the role of anchor-grouting integrated stable control support

In Figure 19 (b), the hollow grouting cable bolt technology is shown where the end anchors are changed to full-length anchors to improve the rigidity and shear resistance of the supporting system. Through grouting, the fractured surrounding rock was provided with high-stress radial restraint, so that the fractured rock mass could exert its stress-strengthening characteristics and provide a reliable foundation for the anchor cable. The formula for the surrounding rock reinforcement theory was derived as follows:

Uniaxial compressive strength of broken surrounding rock $\sigma_{c}$ is given by

$$
\sigma_{c}=\frac{2 c \cdot \cos \varphi}{1-\sin \varphi}
$$

After the process of grouting in the broken surrounding rock, there was an improvement in the cohesion $c$, internal friction angle $\varphi$, and elastic modulus $E$. The uniaxial compressive strength $\sigma_{c}$ is given by

$$
\sigma_{c}^{\prime}=\frac{2(c+\Delta c) \cdot \cos (\varphi+\Delta \varphi)}{1-\sin (\varphi+\Delta \varphi)}
$$

where, $\Delta c$ and $\Delta \varphi$ are the respective increments in the cohesion and internal friction angle, respectively. According to the Heok-Brown guidelines(Eberhardt 2012),

$$
\sigma_{1}=\sigma_{3}+\sqrt{m \sigma_{c} \sigma_{3}+s \sigma_{c}^{2}}
$$

where, $m$ and $s$ are constants for evaluating the rock properties and integrity.

When $\sigma_{1}=0$, the uniaxial tensile strength $\sigma_{t}$ of the rock mass is obtained as

$$
\sigma_{t}=\frac{1}{2} \sigma_{c}\left(m-\sqrt{m^{2}+4 s}\right)
$$

With the increase in the uniaxial compressive strength of the broken surrounding rock after grouting, the tensile strength $\sigma_{t}$ of the strengthened surrounding rock is obtained as

$$
\sigma_{t}^{\prime}=\frac{\left(m^{\prime}-\sqrt{m^{\prime 2}+4 s^{\prime}}\right)(c+\Delta c) \cdot \cos (\varphi+\Delta \varphi)}{1-\sin (\varphi+\Delta \varphi)}
$$

where, $m^{\prime}$ and $s^{\prime}$ are the rock evaluation constants after anchoring. 
Table 3 Change in mechanical parameters of surrounding rock after grouting

\begin{tabular}{|c|c|c|c|c|}
\hline Strength curve of surrounding rock before and after grouting & Mechanical parameters & $\begin{array}{c}\text { Original } \\
\text { parameter values }\end{array}$ & $\begin{array}{l}\text { Parameter } \\
\text { increase/ } \Delta\end{array}$ & $\begin{array}{l}\text { The increasing } \\
\text { rate of tensile } \\
\text { strength/\% }\end{array}$ \\
\hline$\overline{\sigma_{1} \uparrow}$ & \multirow{8}{*}{$\begin{array}{l}\text { Internal friction angle } \\
\qquad \varphi^{\prime}\end{array}$} & \multirow{4}{*}{$2.69 \mathrm{MPa}$} & 1.0 & 37 \\
\hline & & & 1.4 & 52 \\
\hline l compressi & & & 2.0 & 74 \\
\hline & & & 2.7 & 100 \\
\hline Uniaxial compression & & \multirow{4}{*}{$30^{\circ}$} & 5 & 11 \\
\hline & & & 10 & 24 \\
\hline Uniaxial tension $\longleftarrow \xi \longrightarrow$ & & & 15 & 39 \\
\hline$\rightleftarrows$ Tension $\sigma_{t}^{\prime} \sigma_{t} O$ & & & 30 & 115 \\
\hline
\end{tabular}

As shown by the strength curve in Table 3, the parameters of the mechanical properties of the surrounding rock were improved after grouting, and the values of $c, \varphi$, and $E$ of the fissure surrounding rock increased by $66-225 \%, 4-22^{\circ}$, and $14-61 \%$, respectively(Wang, et al. 2019). The analysis showed that the changes in the mechanical parameters $c$ and $\varphi$ after grouting increased the values of $\sigma_{c}$ and $\sigma_{t}$ significantly. From equation (4.18) it is seen that the change in the values of $m$ and $s$ after anchoring did not produce an obvious increase in $\sigma_{t}$; however, when the values of $c$ and $\varphi$ increase in the same proportion, the rate of increase of $\sigma_{t}$ is different. As shown in the above table, when the increase ratio is small, the influence of $\Delta c$ on $\sigma_{t}$ is greater, and when the increase ratio gradually increases, the influence of $\Delta \varphi$ becomes dominant.

\subsection{Design of strengthening support scheme}

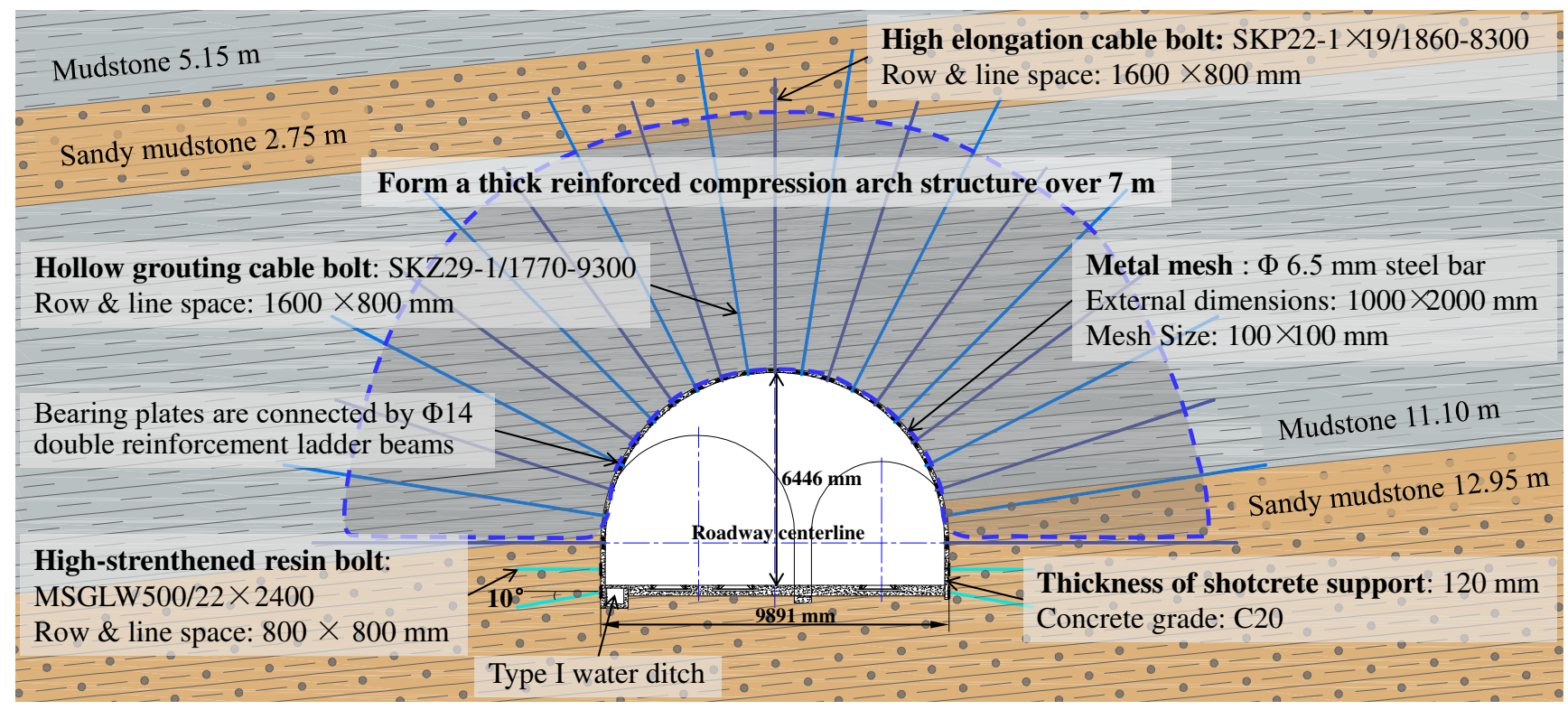

Fig. 20 Schematic of strengthening support scheme for No. 10 intersection

Based on the above field test and theoretical analysis, the design strengthening support scheme of anchor network cable spray + hollow grouting cable bolt support method was adopted (Figure 20) to ensure long-term stability of the surrounding rock of the large-section chamber in the deep well.

The specific support content was as follows: (1) The large deformed roadway under the original support was expanded and cleaned on the whole to meet the design requirements of the original section. (2) In accordance with the characteristics of a large cross-section and gradual cross-section at the intersection of the roadway, the design used high elongation cable bolts and hollow grouting cable bolts on the semicircular section of the roadway to be laid alternately at a $800 \mathrm{~mm}$ interval of the original design plan. This is because the original supporting borehole damaged the integrity of the 
surrounding rock and cracks around the borehole were developed, which was a key area for grouting strengthening. High-strength bolts were used at the bottom corners of both sides of the roadway to strengthen the surrounding rock at the bottom corner. (4) In Figure 20, multiple support methods combine to construct a thick-layered reinforced compression arch of over $7 \mathrm{~m}$ that effectively achieves roof control and reinforcement on both sides of the roadway.

(1) New high-strength hollow grouting cable bolts

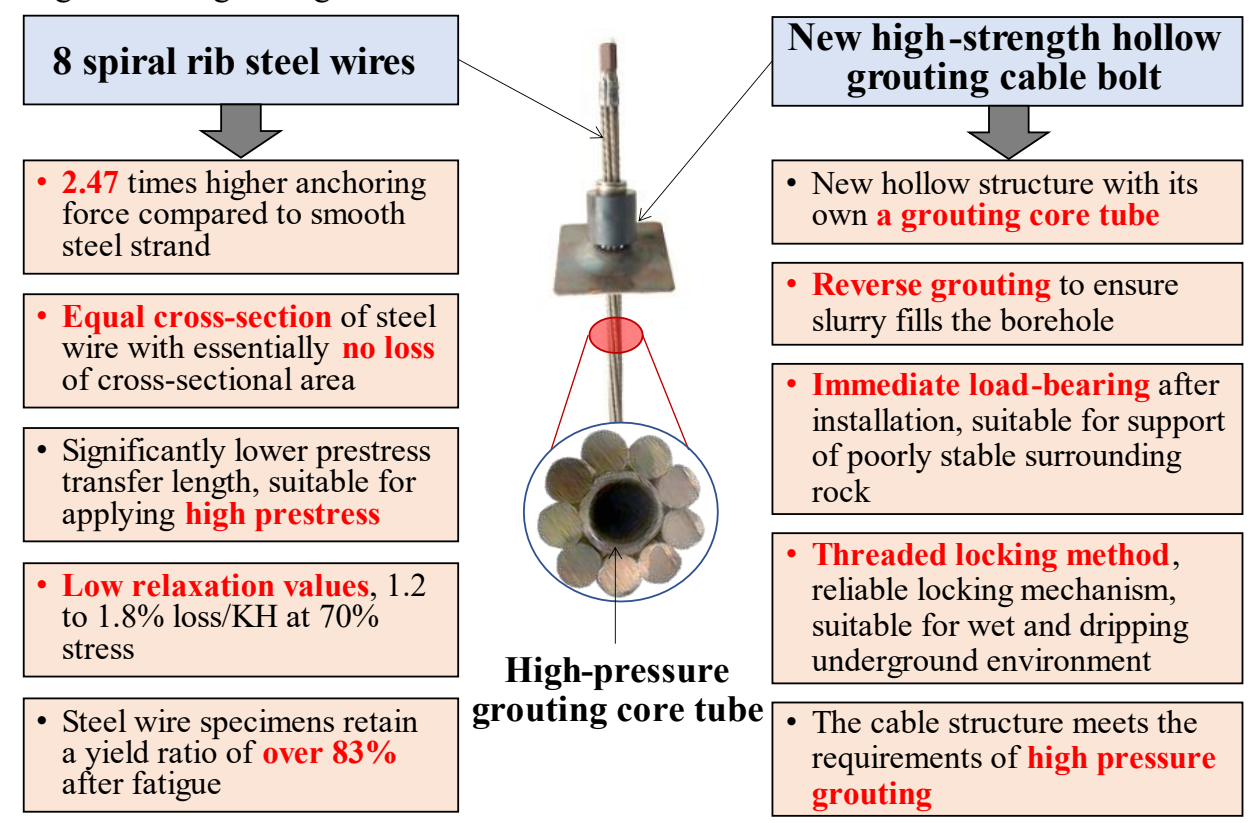

Fig. 21 New hollow grouting cable bolt made of spiral rib steel wire

A new type of hollow grouting cable bolt made of high-strength spiral rib prestressed steel wire was selected for the design. Its structure and advantages of performance are shown in Figure 21. According to previous tests, it was found that the anchoring strength increased by $15-20 \%$, anchoring ductility increased by approximately $25 \%$, and the high-pressure grouting pressure could reach $8 \mathrm{MPa}$ as compared with ordinary grouting anchor cables. In practice, the actual anchoring force increased by two to three times to achieve high-strength anchoring.

(2) New modified cement grouting materials

\begin{tabular}{|c|c|}
\hline Ordinary cement paste & $\begin{array}{l}\text { New modified cement } \\
\text { grouting material }\end{array}$ \\
\hline $\begin{array}{l}\text { Water-cement ratio is } \\
\text { too high so that the } \\
\text { strength is reduced }\end{array}$ & \multirow{2}{*}{\begin{tabular}{|l|} 
- Early-strength、high- \\
strength: the compressive \\
strength of the stone body is \\
increased by 5 and 2.5 times \\
at 3 and 28 d respectively \\
\end{tabular}} \\
\hline $\begin{array}{l}\text { - Poor fluidityand high } \\
\text { grouting resistance }\end{array}$ & \\
\hline \multirow{2}{*}{$\begin{array}{l}\text { - Cement has a large } \\
\text { particle size, making it } \\
\text { difficult for the grout to } \\
\text { be injected into small } \\
\text { cracks }\end{array}$} & $\begin{array}{l}\text { High fluidity performance. } \\
\text { the slurry can fill the entire } \\
\text { gap between the cable body } \\
\text { and the surrounding rock }\end{array}$ \\
\hline & \multirow{2}{*}{$\begin{array}{l}\text { - Micro expansive agent can } \\
\text { compensate for shrinkage } \\
\text { and offset the tensile stress } \\
\text { caused by cement hardening }\end{array}$} \\
\hline $\begin{array}{l}\text { The process of cement } \\
\text { hardened generates } \\
\text { micro-cracks }\end{array}$ & \\
\hline $\begin{array}{l}\text { - Difficulty in controlling } \\
\text { slurry setting time }\end{array}$ & $\begin{array}{l}\text { - Adjustable cement setting } \\
\text { time }\end{array}$ \\
\hline
\end{tabular}

\section{ACZ-I cement grouting additive}

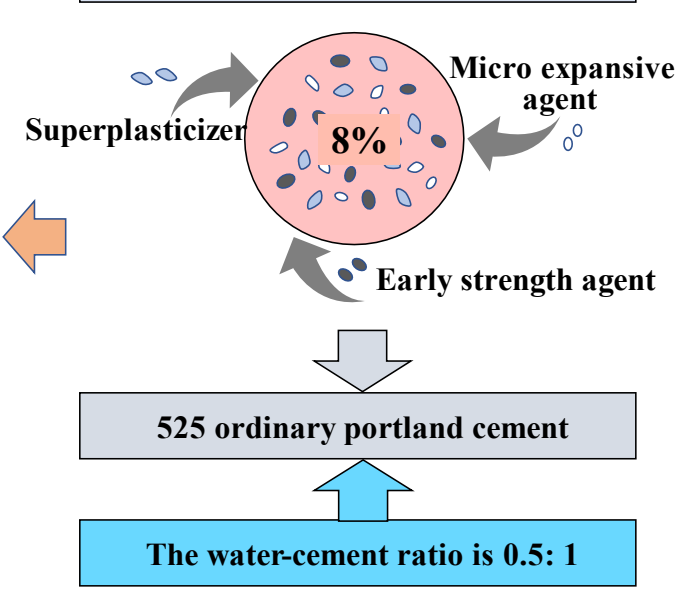

Fig. 22 Schematic of the advantages of modified grouting material

When ordinary cement paste was used in conjunction with hollow grouting cable bolts, the defects were more obvious. Figure 22 shows a new type of modified cement grouting material containing ACZ-I additives that contributes 
significantly to reducing water, plasticizing, strengthening, and micro-expansion of cement materials when grouting and strengthening surrounding rocks, thereby overcoming the current problems of high water-cement ratio, low strength, hardening shrinkage, and large pumping resistance of cement slurries. According to preliminary field testing, the pulling force of the hollow grouting cable bolt utilizing the modified cement slurry was more than twice that of ordinary paste.

(3) Selection of bolt (cable) parameters for strengthening support plan

The new high-strength hollow grouting cable bolt + high elongation cable bolt + high-strength resin bolt were used in the support design, as indicated in the table below.

Table 4 Parameters of anchor bolt (cable) for strengthening support

\begin{tabular}{|c|c|c|c|}
\hline Parameter & Hollow grouting cable bolt & High elongation Cable bolt & High-strengthened resin bolt \\
\hline Model & SKZ29-1/1770-9300 & SKP22-1×19/1860-8300 & MSGLW500/22×2400 \\
\hline Diameter/mm & 29 & 22 & 22 \\
\hline Length/m & 9.3 & 8.3 & 2.4 \\
\hline Tensile strength/MPa & 1770 & 1860 & 500 \\
\hline Breaking force/KN & 600 & 582 & 255 \\
\hline Pre-tightening force/KN & 150 & 200 & 120 \\
\hline Elongation & $4.5 \%$ & $7.0 \%$ & $20.0 \%$ \\
\hline Row \& line space/mm & $1600 \times 800$ & $1600 \times 800$ & $800 \times 800$ \\
\hline Bearing plate $/ \mathrm{mm}$ & $\delta 20 \times 300 \times 300$ & $\delta 20 \times 300 \times 300$ & $\delta 10 \times 150 \times 150$ \\
\hline Resin anchorage agent & MSK2850×1、MSZ2850×3 & MSK2335×1、MSZ2360×2 & MSK2335×1、MSZ2360×1 \\
\hline End anchorage length $/ \mathrm{m}$ & 2.0 & 1.55 & 0.95 \\
\hline Others & Grouting pressure: $\geq 5.0 \mathrm{MPa}$ & & \\
\hline
\end{tabular}

\subsection{Simulation analysis of supporting prestress field}

(1) Support model and surrounding rock compressive stress field

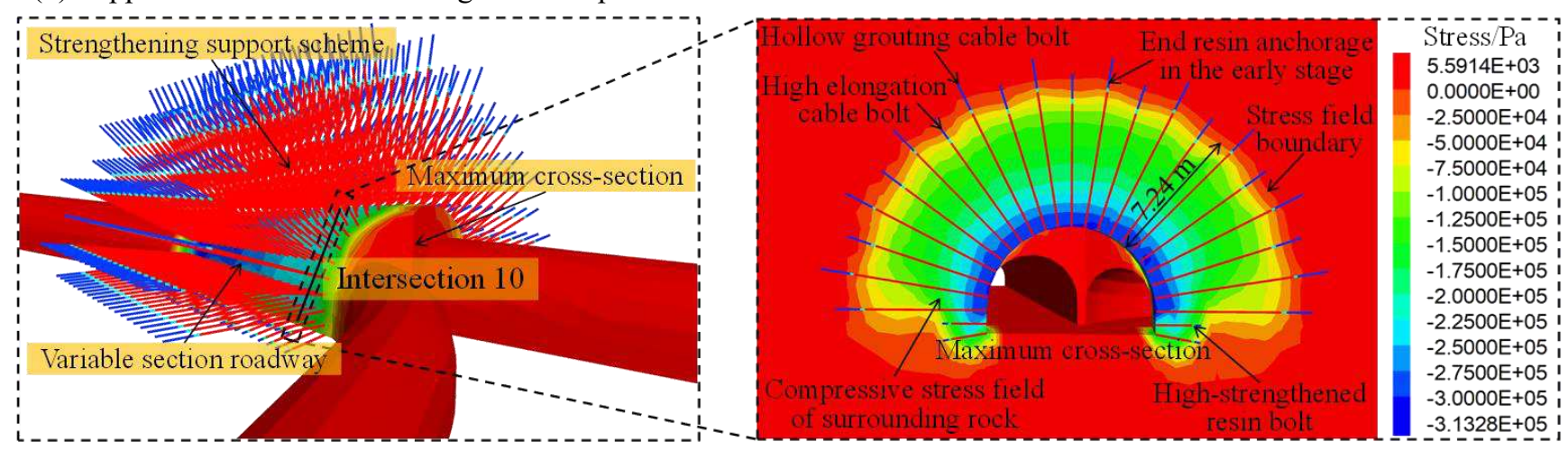

Fig. 23 Roadway supporting structure and surrounding rock compressive stress field

According to the strengthened support plan, the bolt-and-cable support system was simulated in FLAC 3D, as shown in Figure 23, to form the surrounding rock compressive stress field. On examining the stress slices on the compressive stress field at the intersection, it was observed that after installation of the end of the anchor cable, a pressure of $0.02 \sim 3.0$ MPa was applied to the surrounding rock of the free section and the thickness of the compressed surrounding rock was $7.24 \mathrm{~m}$. From the stress cloud diagram, it is seen that the stresses of each anchor cable were cemented with each other to form a complete stress arch that improved the integrity of the surrounding rock to a great extent.

(2) Prestressed field model of the integral support 


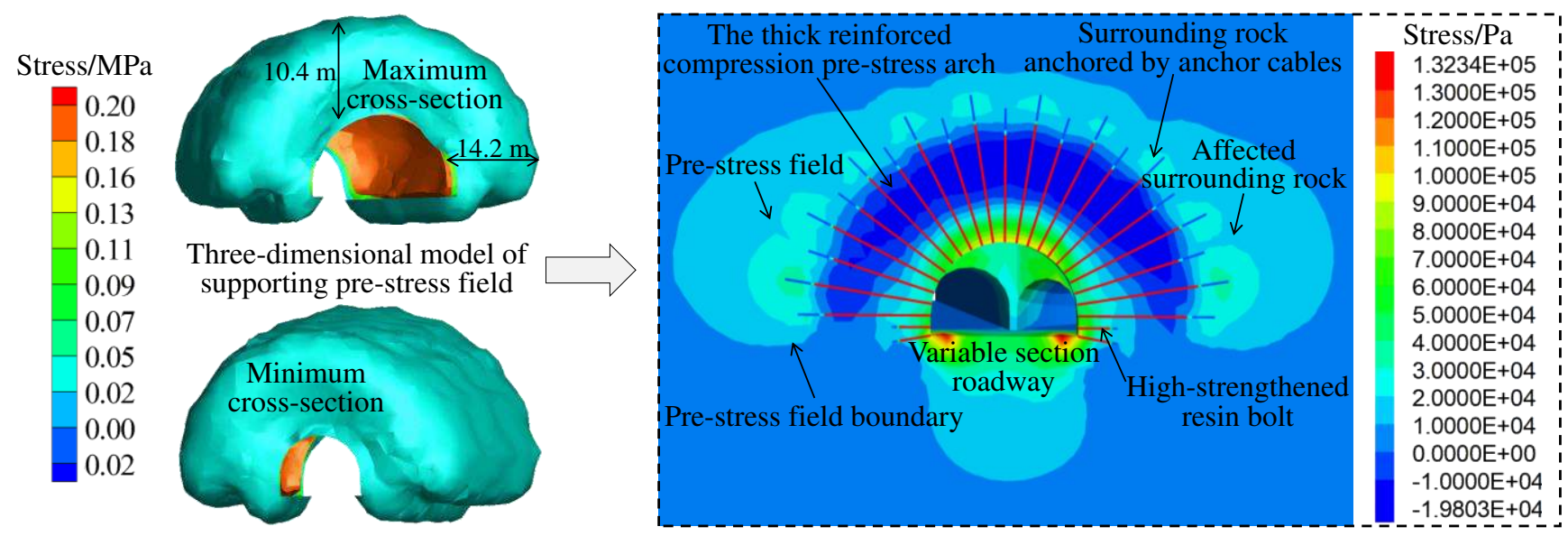

Fig. 24 Strengthened support prestress field model

Figure 24 shows the prestress field model formed by the three-dimensional support system. It is seen that the prestress formed a three-dimensional stress field with a thickness of more than $10 \mathrm{~m}$ along the outer surface of the crossing roadway with variable cross-section and the thickness of the maximum stress field at the two sides was $14.2 \mathrm{~m}$. The stress slice of the three-dimensional model of the prestress field shows that it is bounded by a tensile stress of $0.025 \mathrm{MPa}$ and the hollow grouting cable bolt has a large depth of action; this formed a compressive stress arch greater than $0.02 \mathrm{MPa}$ enabling the surrounding rock to exert its self-carrying capacity.

\subsection{Construction process of strengthening support}

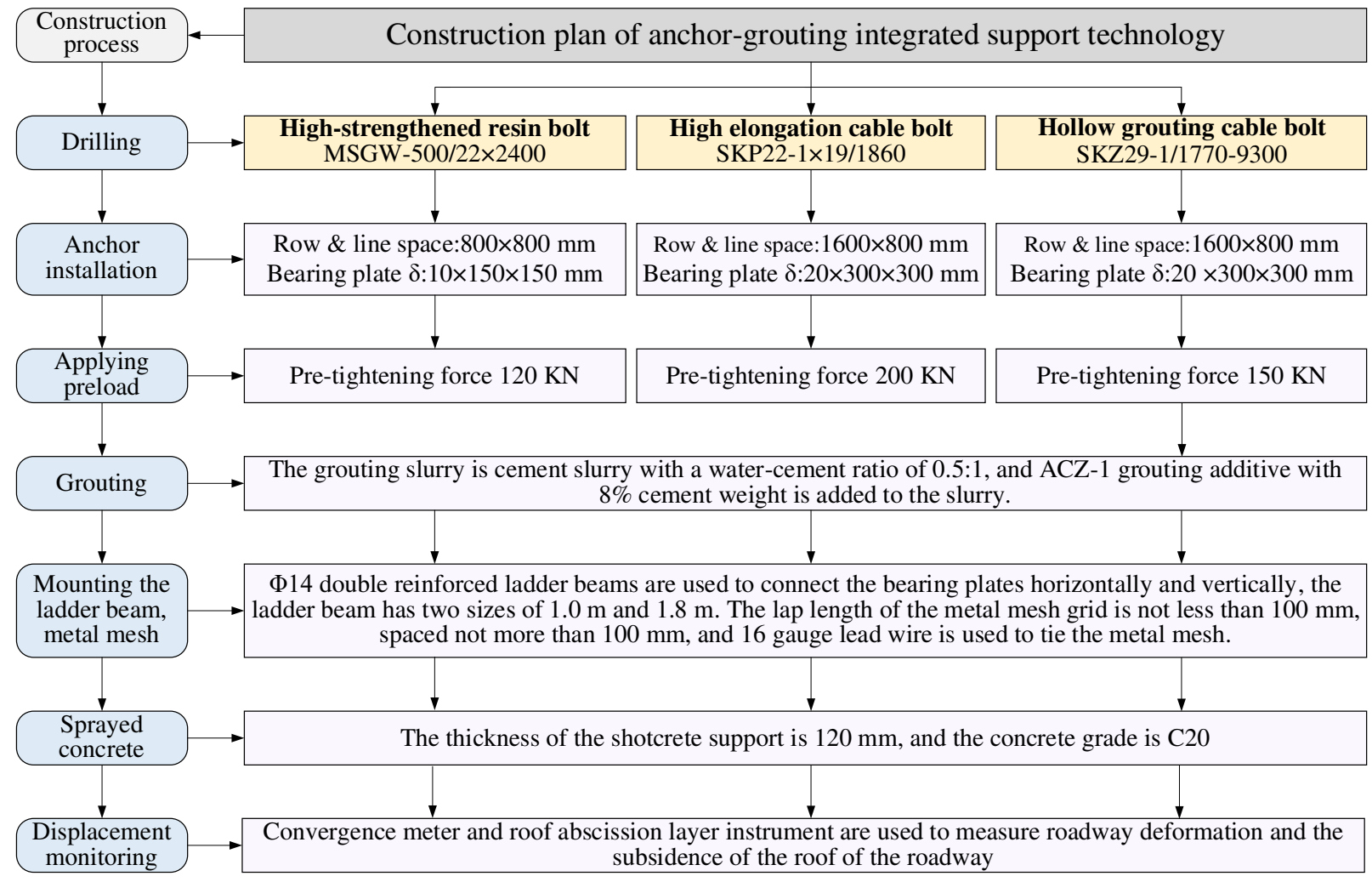

Fig. 25 Flow chart of construction of strengthening support

As shown in Figure 25 of the construction technology, the hollow grouting anchor cable construction involved more steps of installing stop plugs and grouting. When the hole or roof is broken during the drilling construction, the broken body must be put down and the drilling position cleared to facilitate the sealing and control of the drilling depth. Drilling an anchor hole must be carried out in the middle of the roof first and then the two sides from top to bottom. 


\section{Evaluation of effect of strengthening support}

\subsection{On-site implementation effect}

Figure 26 shows an illustration of the field effect of the bolt-grouting support for the No. 10 crossing roadway at the bottom of the air intake shaft depot in the Nanfeng working area. After completion of the construction of the support, its functioning was under observation and the deformation was monitored for 60 days. It was found that the surrounding rock of the roadway was grouted tightly with good integrity, and there was no surface fragmentation, cracking of shotcrete layer, or slag peeling.

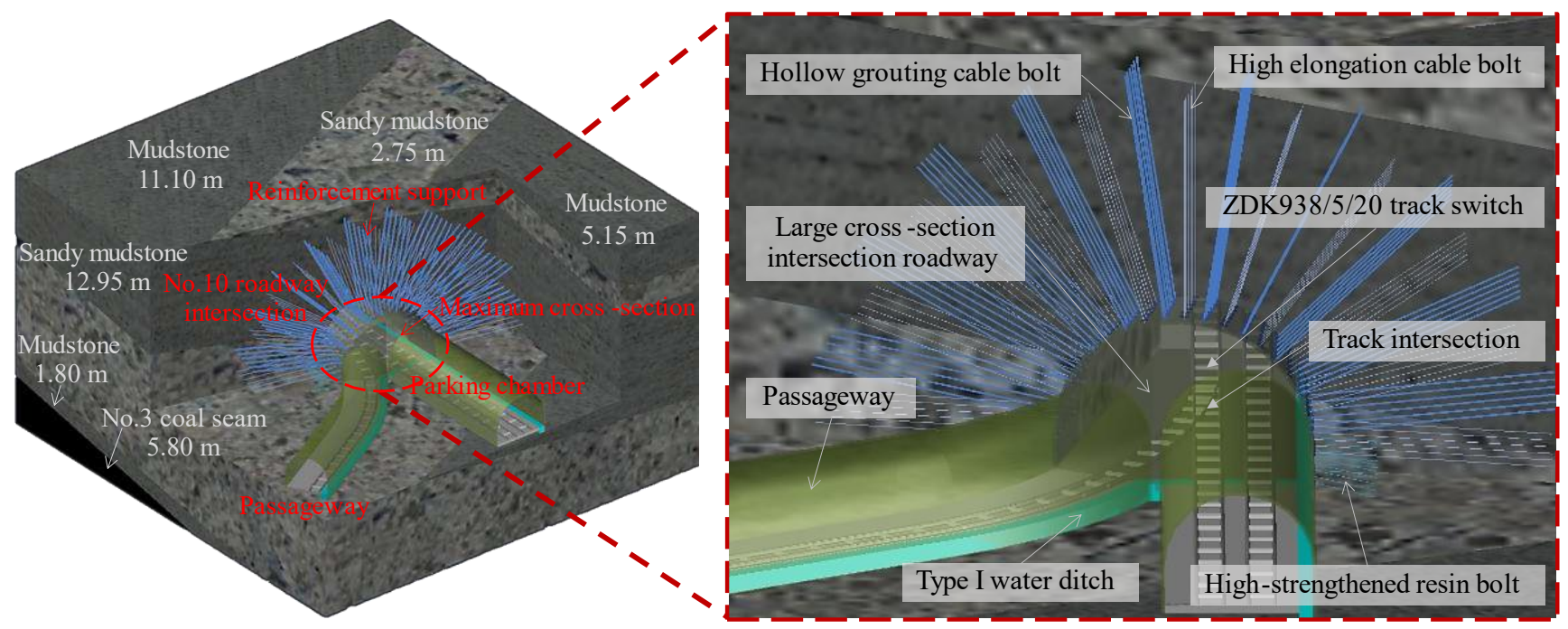

Fig. 26 Effect of strengthening support on site

\subsection{Deformation monitoring analysis}

The convergence deformation of the surrounding rock at the No. 10 intersection was measured and the measurement curve is shown in Figure 27. It is seen that the convergence of the surrounding rock surface is small, deformation at the two sides is similar to that of the floor, and convergence of the roof is small. As compared with later monitoring data, the convergence deformation of the surrounding rock was faster and the rate of convergence was quite high in the first 10 days; however, it was not more than $1.5 \mathrm{~mm} /$ day. The rate of convergence then decreased rapidly and was approximately 0.05 $\mathrm{mm}$ /day for 40 days. This shows that the support form and parameters controlled the convergent deformation of the chamber effectively and maintained a relatively stable state.

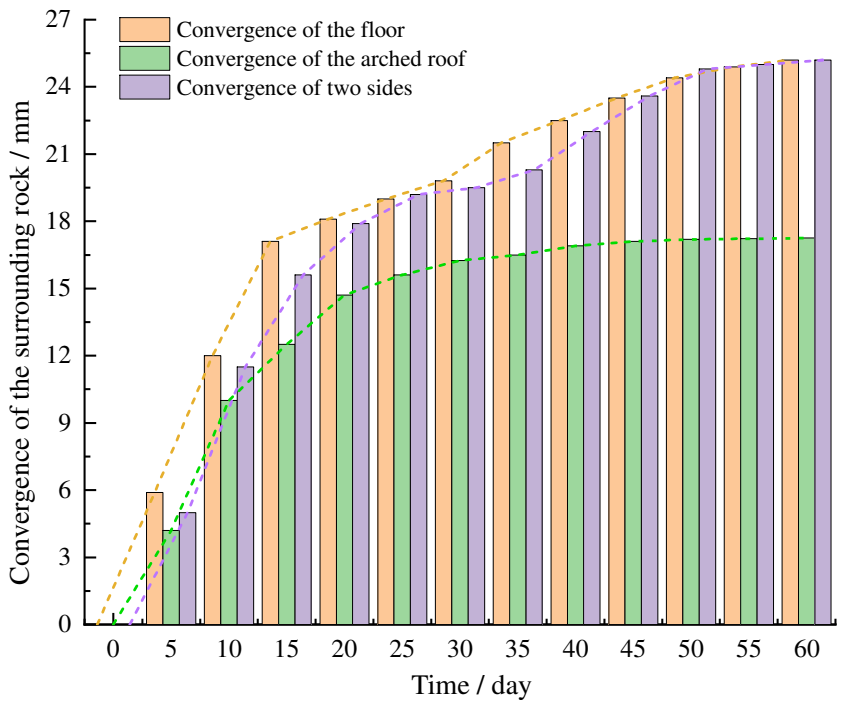

Fig. 27 Deformation monitoring of surrounding rock in the roadway 


\subsection{Evaluation of overall effect}

The surrounding rock at intersection No. 10 was assessed by drilling to evaluate the effect of the support scheme as a whole. The results showed that after carrying out the support scheme, there were cracks in the surrounding rock $(0 \sim 0.4 \mathrm{~m})$ in the hole. The $0.4 \sim 7.4 \mathrm{~m}$ rock layer was grouted and modified with good integrity, and the width of the longitudinal crack was $7.4 \sim 8.3 \mathrm{~m}$. It became smaller and there were no obvious transverse cracks. The $8.3 \sim 13.4 \mathrm{~m}$ rock layer was fairly complete, which showed that the designed anchor-grouting integrated stability control support technology could (i) effectively control the convergence deformation of large soft rock roadway intersection in deep complex geological conditions, (ii) notably reduce the roadway deformation, (iii) greatly extend the period of roadway stability, (iv) ensure adequate maintenance effect, and (v) generate immense economic and social benefits.

\section{Conclusions}

In this study, the No. 10 intersection roadway in the Nanfeng working area of the Wuyang Coal Mine was the subject under investigation to determine the efficacy of support schemes of large-section intersection roadways surrounded by broken rock in deep formations. After on-site monitoring, theoretical analysis, numerical simulation, and construction tests, the following conclusions were drawn:

(1) With the linked reaction of variable cross-sections having a maximum width of $9.9 \mathrm{~m}$, many surrounding chambers, layout under a condition of deep high stress, soft surrounding rock, adjacent faults, and cross-stratification, the intersection roadway exhibited four features, namely loose and broken surrounding rock, plastic failure zone of more than $6 \mathrm{~m}$, serious destruction of roof, and high tectonic stress of nearly $30 \mathrm{MPa}$

(2) According to the simulation of the strain-softening characteristics of the surrounding rock by FLAC 3D, the deflection of the intersection roadway increased with an increase in the size of the cross-section and the roof displacement nearly doubled in the frontal area as compared to that in the normal area. The plastic zone was deep with asymmetric distribution and had a maximum depth up to $6.61 \mathrm{~m}$. It was mainly noticeable in the top and shoulder areas and disappeared gradually in the sidewall and connection between the sidewall and bottom. The stress concentration factor and range increased as compared to other areas of the roadway; they peaked at the frontal area, and the range of stress concentration at the side of the intersection roadway close to the passageway was wider and higher.

(3) In accordance with the compression arch mechanical model based on the parabolic Mohr strength theory, hollow grouting cable bolt and high elongation grouting cable bolt were utilized to build a thick strengthened compression arch more than $7 \mathrm{~m}$ high having a bearing capacity greater by 1.8 to 2.3 times and thickness of the bearing structure increased by 1.76 times as compared to that of the original support scheme. Thus, the construction of a large-depth, high-intensity bearing structure of the surrounding rock was accomplished successfully.

(4) The values of $\sigma_{c}$ and $\sigma_{t}$ increased owing to the increase in the mechanical parameters $c$ and $\varphi$ of the surrounding rock after bolting and slip casting. An increase in the same proportion of $c$ and $\varphi$ caused a different increasing rate of $\sigma_{t}$, and $\Delta c$ influenced $\sigma_{t}$ to a greater extent when the proportion of increase was low; when the proportion of increase rose gradually, the influence of $\Delta \varphi$ became the leading cause of increase in $\sigma_{t}$.

(5) By using a modified cement grouting material and high-strength hollow grouting cable bolt, the drawing force increased to more than twice that of the cement paste; this enhanced the extent of filling of cracks and mechanical properties of the surrounding rock significantly. Based on the supporting stress field, the surrounding rock (7.24 m) was compacted and strengthened, providing a solid foundation for the attachment of the bolt (cable) support. According to the results of field monitoring, the convergence of the gallery was less than $30 \mathrm{~mm}$ in 60 days, indicating that stability control of the gallery was achieved effectively.

Acknowledgements This work was financially supported by the National Natural Science Foundation of China (Grant No. 52074296, 52004286), the China Postdoctoral Science Foundation (Grant No. 2020T130701, 2019M650895). 


\section{Declarations}

Conflict of interest The authors declare that they do not have any commercial or associative interest that represents a conflict of interest in connection with the work submitted.

Ethical approval The experiments comply with the current laws of China.

\section{References}

Cai MF and Brown Edwin T. (2017) Challenges in the mining and utilization of deep mineral resources. Engineering 3(4): 432-433.

Chen XJ, Li LY, Wang L and Qi LL (2019) The current situation and prevention and control countermeasures for typical dynamic disasters in kilometer-deep mines in China. Saf Sci 115: 229-236.

Liu CR (2011) Distribution laws of in-situ stress in deep underground coal mines. Procedia Engineering 26: $909-917$.

Fairhurst C (2017) Some challenges of deep mining. Engineering 3(4): 527-537.

Xie HP, Gao MZ, Zhang R, Peng GY, Wang WY and Li AQ (2018) Study on the mechanical properties and mechanical response of coal mining at 1000m or deeper. Rock Mech Rock Eng 52(5): 1475-1490.

Wagner H (2019) Deep mining: a rock engineering challenge. Eng Mech Rock Eng 52(5): 1417-1446.

Ranjith PG, Zhao J, Ju MH, De Silva Radhika VS, Rathnaweera TD and Bandara AKMS. (2017) Opportunities and challenges in deep mining: a brief review. Engineering 3(4): 546-551.

Pan R, Wang Q, Jiang B, Li SC, Sun HB, Qin Q, Yu HC and Lu W (2017) Failure of bolt support and experimental study on the parameters of bolt-grouting for supporting the roadways in deep coal seam. Eng Fail Anal 80: 218-233.

Yang RS, Li YL, Guo DM, Yao L, Yang TM and Li TT (2017) Failure mechanism and control technology of water-immersed roadway in high-stress and soft rock in a deep mine. Int J Min Sci Technol 27(2): 245-252.

Xie SR, Pan H, Zeng JC, Wang E, Chen DD, Zhang T, Peng XJ, Yang JH, Chen F and Qiao SX (2019) A case study on control technology of surrounding rock of a large section chamber under a 1200-m deep goaf in Xingdong coal mine, China. Eng Fail Anal 104: 112-125.

Kang YS, Liu QS, Gong GQ and Wang HC (2014) Application of a combined support system to the weak floor reinforcement in deep underground coal mine. Int J Min Sci Technol 71: 143-150.

Huang WP, Yuan Q, Tan YL, Wang J, Liu GL, Qu GL and Li C (2018) An innovative support technology employing a concrete-filled steel tubular structure for a 1000-m-deep roadway in a high in situ stress field. Tunn Undergr Space Technol 73: 26-36.

Li G, Ma FS, Guo J, Zhao HJ and Liu G (2020) Study on deformation failure mechanism and support technology of deep soft rock roadway. Eng Geol 264: 105262.

Zhang JP, Liu LM, Cao JZ, Yan X and Zhang FT (2018) Mechanism and application of concrete-filled steel tubular support in deep and high stress roadway. Constr Build Mater 186: 233-246.

Wang Q, Pan R, Jiang B, Li SC, He MC, Sun HB, Wang L, Qin Q, Yu HC and Luan YC (2017) Study on failure mechanism of roadway with soft rock in deep coal mine and confined concrete support system. Eng Fail Anal 81: 155-177.

Yang SQ, Chen M, Jing HW, Chen KF and Meng B (2017) A case study on large deformation failure mechanism of deep soft rock roadway in Xin'An coal mine, China. Eng Geol 217: 89-101.

Wang MY, Zhang N, Li J, Ma LJ and Fan PX (2015) Computational method of large deformation and its application in deep mining tunnel. Tunn Undergr Space Technol 50: 47-53.

Huang J, Zhang YM, Zhu LS and Wang T (2016) Numerical simulation of rock cutting in deep mining conditions. Int J Rock Mech Min Sci 84: 80-86. 
Li XF, Wang SB, Malekian R, Hao SQ and Li ZX (2016) Numerical simulation of rock breakage modes under confining pressures in deep mining: an experimental investigation. IEEE Access 4: 5710-5720.

Peng R, Meng X, Zhao G, Li Y and Zhu J (2018) Experimental research on the structural instability mechanism and the effect of multi-echelon support of deep roadways in a kilometre-deep well. PLoS One 13(2): e0192470.

Shreedharan S and Kulatilake PHSW (2015) Discontinuum-equivalent continuum analysis of the stability of tunnels in a deep coal mine using the distinct element method. Rock Mech Rock Eng 49(5): 1903-1922.

Wang H, Jiang C, Zheng PQ, Li N and Zhan YB (2020) Deformation and failure mechanism of surrounding rocks in crossed-roadway and its support strategy. Eng Fail Anal 116: 104734.

Zhang HQ, Miao XX, Zhang GM, Wu Y and Chen YL (2017) Non-destructive testing and pre-warning analysis on the quality of bolt support in deep roadways of mining districts. Int J Min Sci Technol 27(6): 989-998.

Kang HP, Lin J and Fan MJ (2015) Investigation on support pattern of a coal mine roadway within soft rocks — a case study. Int J Coal Geol 140: 31-40.

Yu KP, Ren FY, Puscasu R, Lin P and Meng QG (2020) Optimization of combined support in soft-rock roadway. Tunn. Undergr Space Technol 103: 103502.

Zhang CY, Pu CZ, Cao RH, Jiang TT and Huang G (2019) The stability and roof-support optimization of roadways passing through unfavorable geological bodies using advanced detection and monitoring methods, among others, in the Sanmenxia Bauxite Mine in China’s Henan Province. Bull Eng Geol Environ 78(7): 5087-5099.

Tan YL, Fan DY, Liu XS, Song SL, Li XF and Wang HL (2019) Numerical investigation of failure evolution for the surrounding rock of a super - large section chamber group in a deep coal mine. Energy Sci Eng 7(6): 3124-3146.

Huang X, Liu QS, Liu B, Liu KD and Huang SB (2014) Experimental research on the mechanical behavior of deep soft surrounding rock tunneling by TBM. J China Coal Soc 39(10): 1977-1986. (in Chinese)

Lu YL, Wang LG, Yang F, Li YJ and Chen HM (2010) Post-peak strain softening mechanical properties of weak rock. Chin J Rock Mech Eng 29(3): 640-648. (in Chinese)

Alonso E, Alejano LR, Varas F, Fdez-Manin G and Carranza-Torres C (2003) Ground response curves for rock masses exhibiting strain-softening behaviour. Int J Numer Anal Methods Geomech27(13): 1153-1185.

Lee YK and Pietruszczak S (2008) A new numerical procedure for elasto-plastic analysis of a circular opening excavated in a strain-softening rock mass. Tunn Undergr Space Technol 23(5): 588-599.

Zhang F, Sheng Q, Zhu ZQ and Zhang YH (2008) Study on post-peak mechanical beha viour and strain-softening model of three gorges granite. Chin J Rock Mech Eng 27(S1): 2651-2655. (in Chinese)

Li CG, Ge XR, Zheng H and Wang SL (2006) Two-parameter parabolic Mohr strength criterion and its damage regularity. Key Engineering Materials 306-308: 327-332.

Eberhardt E (2012) The Hoek-Brown failure criterion. Rock Mech Rock Eng 45(6): 981-988.

Wang Q, Qin Q, Jiang B, Yu HC, Pan R and Li SC (2019) Study and engineering application on the bolt-grouting reinforcement effect in underground engineering with fractured surrounding rock. Tunn Undergr Space Technol 84 : 237-247. 